Research Article

\title{
Optimization Analysis of Settlement Parameters for Postgrouting Piles in Loess Area of Shaanxi, China
}

\author{
Zhijun Zhou $\mathbb{D}^{1},{ }^{1}$ Shanshan Zhu, ${ }^{1}$ Xiang Kong, ${ }^{1,2}$ Jiangtao Lei $\mathbb{D},{ }^{1}$ and Tong Liu $\mathbb{D}^{3}$ \\ ${ }^{1}$ School of Highway, Chang'an University, Xi'an, Shaanxi 710064, China \\ ${ }^{2}$ China State Construction Silk Road Investment Group Co.Ltd, Xi'an, Shaanxi 710065, China \\ ${ }^{3}$ School of Science, Xi'an University of Architecture and Technology, Xi'an, Shaanxi 710055, China \\ Correspondence should be addressed to Tong Liu; liutong@xauat.edu.cn
}

Received 6 January 2019; Revised 2 March 2019; Accepted 27 March 2019; Published 18 April 2019

Academic Editor: Giulio Dondi

Copyright (C) 2019 Zhijun Zhou et al. This is an open access article distributed under the Creative Commons Attribution License, which permits unrestricted use, distribution, and reproduction in any medium, provided the original work is properly cited.

\begin{abstract}
The settlement calculation of postgrouting piles is complex and depends on the calculation method and parameters. Static load tests were conducted to compare the settlement characteristics of nongrouting and postgrouting piles, and three vital parameters in the layer-wise summation method were revised to predict the settlement of postgrouting piles. The elastic compression coefficient was deduced based on the Mindlin-Geddes method by considering the influence of the change in the pile side resistance distribution and end resistance ratio on the elastic compression after grouting. The relationship between the compression modulus and soil gravity stress and cone penetration resistance were established, respectively, using experimental data. The optimum value of the settlement empirical coefficient was determined using regional data. Finally, we used the postgrouting pile of the Wuqi-Dingbian expressway as a practical example. The results obtained from the layer-wise summation method after parametric optimization were close to the measured values. The results of this study provide reference data and guidance for the settlement calculation of postgrouting piles in this area.
\end{abstract}

\section{Introduction}

Loess is widely distributed worldwide and accounts for about $1 / 10$ of the global land area [1]. The Loess Plateau in northwestern China is the most extensive loess accumulation area in the world and represents $72.4 \%$ of China's loess area. In 2013, the state put forward the strategic conception of the "New Silk Road Economic Belt"; a large part of this area belongs to the Loess region, which results in new opportunities and challenges for infrastructure construction in the Loess area [2]. The settlement of superstructures is especially a concern for bridges that require high design accuracy for the foundation design. However, the nonuniform compressibility of loess often results in significant pile settlement [3-5]. As a means of increasing the bearing capacity and reducing the settlement of pile foundations, the postgrouting technique has become a popular method for cast-in-place pile foundation construction [6-13]. However, research on the settlement of postgrouting piles is relatively limited although the settlement is a key factor in pile design. Therefore, in this study, we investigate the postgrouting technique for pile foundation construction to predict the settlement of postgrouting piles in loess areas.

In past decades, many methods have been used to calculate the settlement of piles, such as the theoretical loadtransfer method [14-16], the elastic theory method [17, 18], the shearing deformation method [19], numerical computation methods [20-25], and the layer-wise summation method [26]. Some scholars have investigated the adaptability of the postgrouting technique in different bearing strata and the factors influencing the settlement and deformation $[9,27]$. Other scholars have considered the soil parameters and proposed an iterative solution for a single pile after studying the interaction between the slurry and soil; a settlement calculation method was put forward based on the shearing deformation and the theoretical loadtransfer methods [28-30]. Many scholars have used numerical procedures to simulate postgrouting piles to 
determine the bearing capacity and settlement characteristics; the results showed that the simulated values were in good agreement with the measured values [31].

Although the abovementioned methods can predict the settlement of postgrouting piles, these methods have the disadvantage of poor applicability due to the complexity of the soil after grouting. Therefore, although research on piles settlement using the layer-wise summation method is relatively limited, it is actually the simplest and most practical method. For example, the settlement calculation method described in the latest edition of the Chinese Technical Code for Building Pile Foundations [32] is based on layer-wise summation method, making it the most widely used method in engineering design calculation. However, the values of the calculation parameters are not given in this code because there are regional differences in the parameters for the settlement of postgrouting piles. In this study, the layer-wise summation method is used. We conduct a static load test, indoor test, and static cone penetration test on the WuqiDingbian expressway and determine the optimum values of three parameters affected by postgrouting. Finally, we compare the results obtained from the layer-wise summation method after parametric optimization with the measured values; a good agreement is obtained. The results of this study provide data and guidance for the settlement calculation of postgrouting piles in the loess area of northern Shaanxi in China.

\section{Site Condition and Test Methods}

2.1. Site Condition. The Wuqi-Dingbian expressway (Figure 1), which crosses Wuqi County and Dingbian County in China, is a key project of Shaanxi Province construction began in 2015. The route starts from Zoumatai in the east of Wuqi County and ends at Shijingzi in the southeast of Dingbian County; the expressway has a length of $92.217 \mathrm{~km}$. The study area is located in the middle point of this route. The abutments on both sides of the bridge are located in the loess hill region (the loess hill region refers to the geomorphology resulting from loess erosion (C) Baidu Encyclopedia).

A geological survey and drilling indicated no surface water and groundwater at the drilling depth. The upper soil layer is loessial loess with a thickness of $1.8 \mathrm{~m}$, and all below $1.8 \mathrm{~m}$ are old loess. The bottoms of the piles are located in the deep old loess layer. To ensure the safety and stability of the structure, the piles have to be tested.

2.2. Test Methods. The test consisted of indoor and field tests. The indoor tests included a moisture content test (Figure 2(a)), a compression test (Figure 2(b)), a direct shear test (Figure 2(c)), and an unconfined compressive strength test (Figure $2(\mathrm{~d})$ ). The field tests included a static cone penetration test (Figure 2(e)) and a static load test (Figure 4(b)). The moisture content of the soil samples was determined from the moisture content test, the void ratio and coefficient of compressibility were obtained from the compression test, the cohesion and internal friction angle were obtained from the direct shear test, and the unconfined compressive strength was obtained from the unconfined compressive strength test; the indoor test results are shown in Table 1.

In the field test, TS1 was the nongrouting pile and TS2 was the postgrouting pile. The length of the test piles and anchor piles were $25 \mathrm{~m}$ and $30 \mathrm{~m}$, respectively, and they had the same diameter of $1.5 \mathrm{~m}$. The test piles were $1.5 \mathrm{~m}$ above the ground to conduct the static load test. The pile body and the aboveground part consisted of C30 and C40 concrete, respectively.

The installation process of the test pile was as follows: (1) a rotary drilling method with high bearing capacity was used to excavate the pile hole. The location of the pile was determined, and the drilling rig (Figure 3(a)) was moved into position. (2) The initial drilling speed should not be too fast, i.e., no more than $2 \mathrm{~m} / \mathrm{h}$, and the subsequent speed should be no more than $3 \mathrm{~m} / \mathrm{h}$. The technical operating regulations [32] should be strictly observed during the drilling process. (3) The first hole cleaning was carried out when the drilling reached the desired depth, rotary drill bit (Figure 3(b)) sweeps several laps in situ to clean sediment at pile bottom. A plumb bob was placed into the hole to measure the sediment thickness of the two test piles after the hole cleaning; the values were $37 \mathrm{~mm}$ and $22 \mathrm{~mm}$, respectively, and met the requirements of being less than $50 \mathrm{~mm}$. (4) Finished rolled threaded reinforcing bars with a diameter of $25 \mathrm{~mm}$ were welded onto a steel reinforcement cage (Figure 3(c)), and the reinforcement ratio was $0.44 \%$; 21 strain gauges (Figure 3(d)) were evenly attached to the steel reinforcement cage at 7 locations (Figure 4(a)) for each pile, and the steel reinforcement cage was placed into the hole [33]. (5) Due to sand and stone precipitation in the mud and the slurry falling into the hole by rubbing against the hole wall when the steel reinforcement cage and the pipe (Figure 3(e)) were inserted, a second hole cleaning was conducted by using the pipe before grouting; the thickness of the sediment below the hole was measured. The sediment thicknesses of the two piles were $33 \mathrm{~mm}$ and $41 \mathrm{~mm}$, respectively, which was in agreement with the code [32] that specifies less than $50 \mathrm{~mm}$. There was little difference in the sediment thickness; therefore, the bearing capacity of the pile foundation was only slightly affected. (6) The overgrouting height was $1.0 \mathrm{~m}$, and finally the floating slurry on the top of the pile is removed and the pile body is maintained. (7) Installed grouting equipment (Figure 3(f)) after concrete strength of TS2 pile reaches $75 \%$. The slurry density of the watercement ratio of 0.4 is $1700 \mathrm{~kg} / \mathrm{m}^{3}$. The equation for determining the grouting quantity is provided in the code [34]:

$$
G_{\mathrm{c}}=a_{\mathrm{p}} d
$$

where $G_{\mathrm{c}}$ is the quantity of grout, $a_{\mathrm{p}}$ is the grouting coefficient, and $d$ is the diameter of the pile. According to the characteristics of the bearing stratum at the pile end, the reference value of the grouting coefficient $a_{\mathrm{p}}$ in the reference code [34] is 2.1 and the diameter of TS2 is $1.5 \mathrm{~m}$; therefore, the estimated grouting quantity is $3.15 t$ and the grouting rate is less than $75 \mathrm{~L} / \mathrm{min}$. The grouting stopped when the grouting quantity reached $3.15 t$; at this time, the grouting 

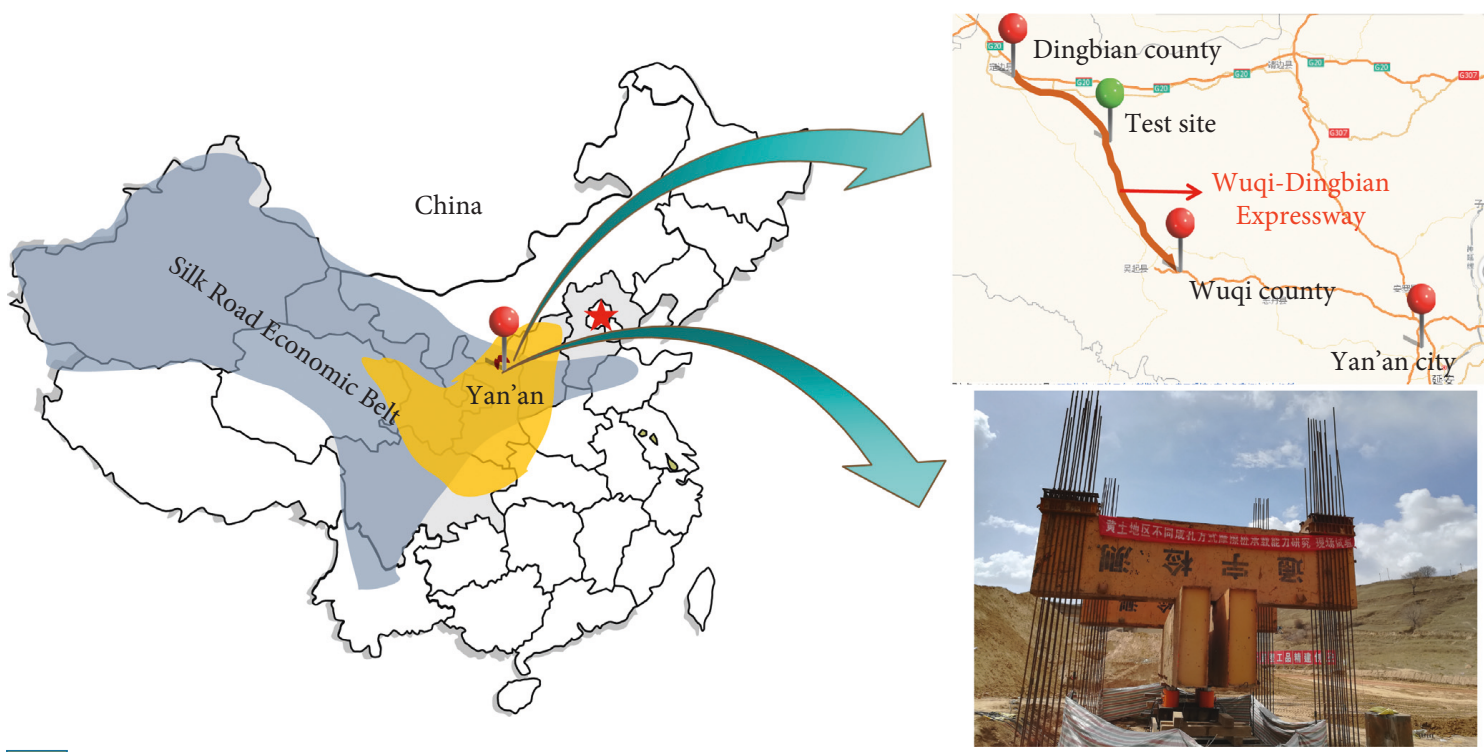

FIgURE 1: The location of the study area (map data @ 2018 Baidu maps; loess area distribution @ Baidu encyclopedia; the picture was taken by Zhijun Zhou).

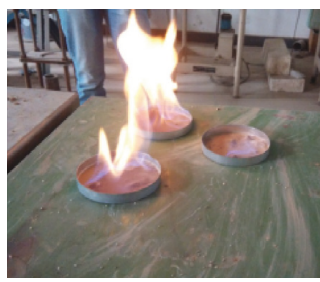

(a)

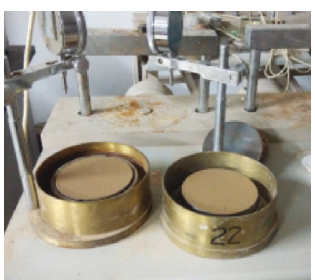

(b)

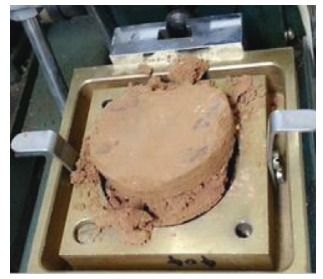

(c)

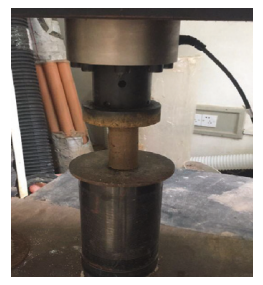

(d)

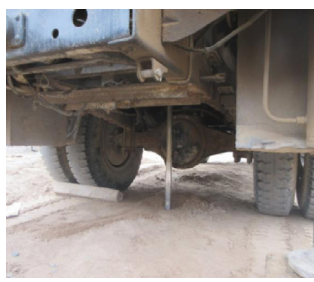

(e)

Figure 2: Indoor and field tests. (a) Moisture content test. (b) Compression test. (c) Direct shear test. (d) Unconfined compressive strength test. (e) Static cone penetration test.

TABLe 1: Physical properties of the soil layers.

\begin{tabular}{|c|c|c|c|c|c|c|c|c|}
\hline $\begin{array}{l}\text { Name and } \\
\text { layer number }\end{array}$ & $\begin{array}{l}\text { Depth, } \\
h(\mathrm{~m})\end{array}$ & $\begin{array}{l}\text { Density } \\
\left(\mathrm{g} / \mathrm{cm}^{3}\right)\end{array}$ & $\begin{array}{l}\text { Moisture } \\
\text { content, } \omega \\
(\%)\end{array}$ & $\begin{array}{l}\text { Void } \\
\text { ratio, } e\end{array}$ & $\begin{array}{c}\text { Coefficient of } \\
\text { compressibility, } a_{1-2} \\
\left(\mathrm{MPa}^{-1}\right)\end{array}$ & $\begin{array}{l}\text { Cohesion, } \\
c(\mathrm{kPa})\end{array}$ & $\begin{array}{c}\text { Internal } \\
\text { friction angle, } \\
\varphi\left({ }^{\circ}\right)\end{array}$ & $\begin{array}{c}\text { Unconfined } \\
\text { compressive strength } \\
(\mathrm{kPa})\end{array}$ \\
\hline $\begin{array}{l}\text { 1. Loessial } \\
\text { soil, } Q_{4}^{\mathrm{pl}}\end{array}$ & $0 \sim 1.8$ & 1.68 & 16.3 & 0.883 & 0.35 & 6.8 & 28.4 & 1.64 \\
\hline $\begin{array}{l}\text { 2. Old loess, } \\
\mathrm{Q}_{2}^{\text {Eol }}\end{array}$ & $1.8 \sim>50$ & 1.85 & 7.9 & 0.586 & 0.12 & 30.5 & 25.8 & 14.5 \\
\hline
\end{tabular}

pressure reached 4.0 $\mathrm{MPa}$. The distributions of soil and the spacing of stress gauges (Figure 3(d)) along the pile shaft are shown in Figure 4(a).

In the static load test, an anchor pile beam counterforce device was used (Figure 4(b)); the load was applied in increments using eight identical hydraulic jacks (Figure 4(b), (i)) at the top of the pile. The loading-unloading method was based on the Chinese Technical Code for Testing of Building Foundation Piles (JGJ106-2014) [34]. The magnitude of the first load step was double that of the subsequent load steps. The first load step was $2000 \mathrm{kN}$, and the load increment was $1000 \mathrm{kN}$. Each load increment was maintained after loading until two consecutive displacements during one hour were less than $0.1 \mathrm{~mm}$ and occurred twice continuously [33].

\section{Static Load Test Results and Calculation Process}

3.1. Settlement Calculation. The settlement of the pile head was calculated by using the average of 4 automatic displacement acquisition instruments (Figure 4(b), (ii)) installed at the pile head after each loading step was completed. The settlement of two piles measured under various loads is shown in Table 2, among which $s_{1}, s_{2}, s_{3}$, and $s_{4}$ are the 


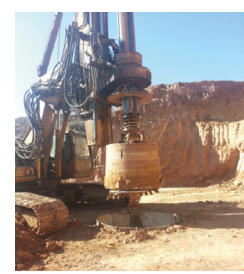

(a)

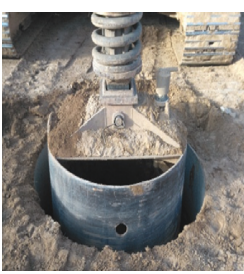

(b)

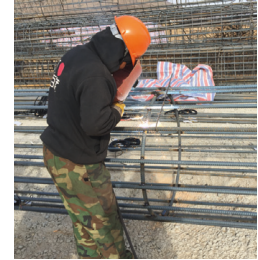

(c)

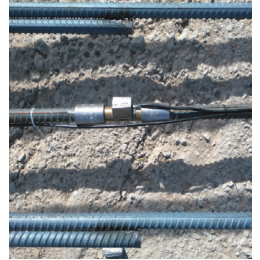

(d)

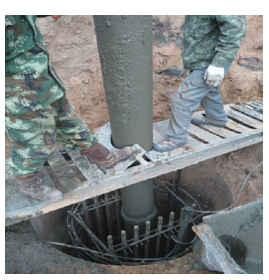

(e)

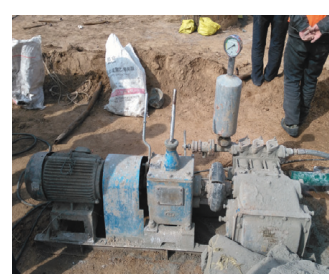

(f)

Figure 3: (a) Drilling rig. (b) Drill bit. (c) Steel reinforcement cage. (d) Reinforcement stress gauge. (e) Pipe. (f) Grouting equipment.

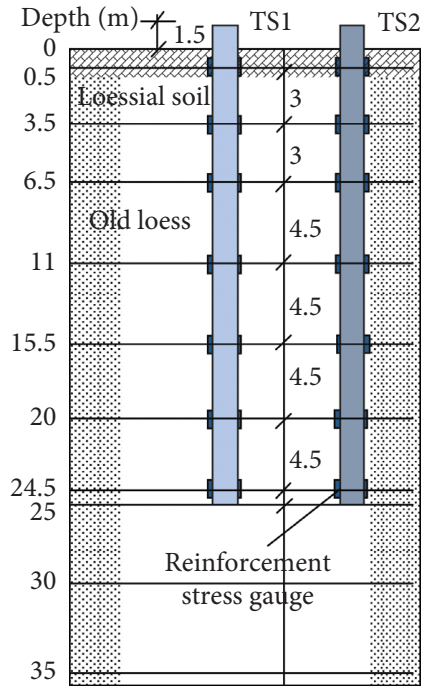

(a)

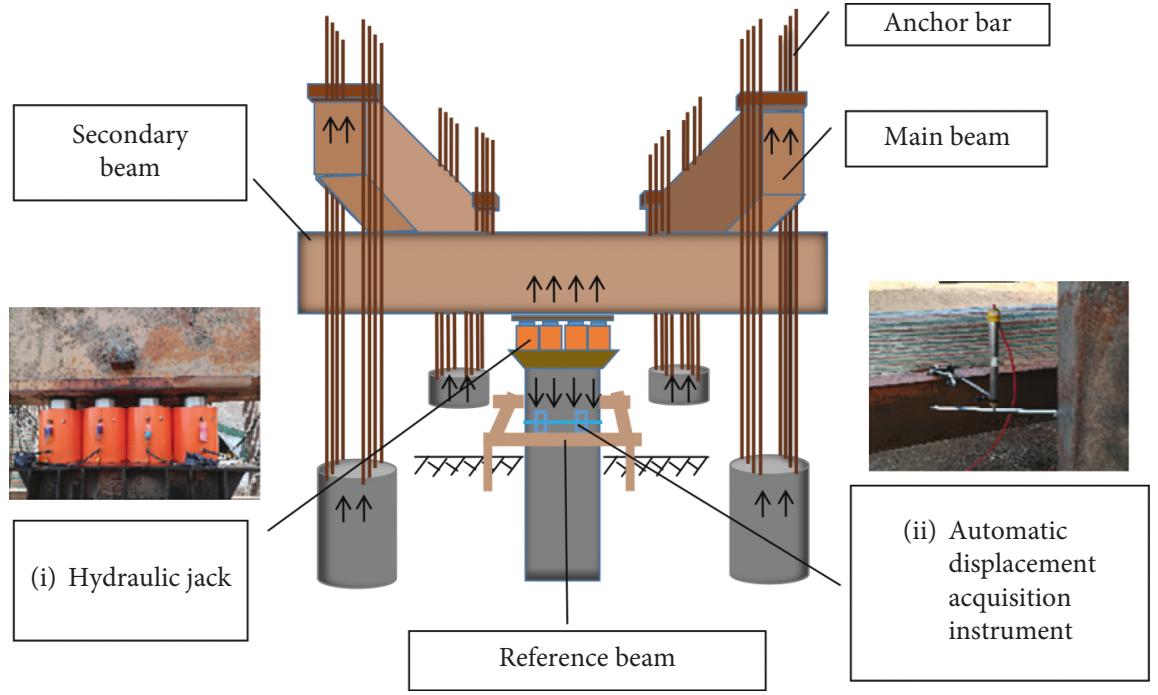

(b)

FIgURE 4: (a) The distributions of soil and the spacing of stress gauges along the pile shaft. (b) Anchor pile beam counterforce device consisting of (i) hydraulic jack, (ii) automatic displacement acquisition instrument, anchor bar, main beam, secondary beam, and reference beam.

TABLE 2: Settlement of two piles measured under various loads.

\begin{tabular}{|c|c|c|c|c|c|c|c|c|c|c|c|c|c|c|}
\hline Load $(\mathrm{kN})$ & 2000 & 3000 & 4000 & 5000 & 6000 & 7000 & 8000 & 9000 & 10000 & 11000 & 12000 & 13000 & 14000 & 15000 \\
\hline$s_{1}(\mathrm{~mm})$ & 0.16 & 0.35 & 0.36 & 0.45 & 0.07 & 0.77 & 1.11 & 4.11 & 15.56 & 21.12 & 23.64 & & & \\
\hline$s_{2}(\mathrm{~mm})$ & 0.22 & 0.33 & 0.38 & 0.43 & 0.06 & 0.89 & 1.24 & 4.00 & 13.87 & 21.72 & 34.22 & & & \\
\hline$s_{3}(\mathrm{~mm})$ & 0.23 & 0.32 & 0.34 & 0.45 & 0.09 & 0.90 & 1.20 & 3.89 & 14.53 & 19.80 & 29.66 & & & \\
\hline$s_{4}(\mathrm{~mm})$ & 0.23 & 0.44 & 0.44 & 0.43 & 0.13 & 0.76 & 1.09 & 3.16 & 15.00 & 20.43 & 32.96 & & & \\
\hline $\bar{s}(\mathrm{~mm})$ & 0.21 & 0.36 & 0.38 & 0.44 & 0.07 & 0.83 & 1.16 & 3.79 & 14.74 & 20.77 & 30.12 & & & \\
\hline$s_{5}(\mathrm{~mm})$ & 0.06 & 0.49 & 1.00 & 0.30 & 0.014 & 0.024 & 1.09 & 0.24 & 1.08 & 0.97 & 1.11 & 1.3 & 0.84 & 2.87 \\
\hline$s_{6}(\mathrm{~mm})$ & 0.07 & 0.5 & 1.11 & 0.41 & 0.007 & 0.030 & 1.10 & 0.25 & 0.99 & 0.97 & 1.21 & 1.16 & 0.66 & 3.09 \\
\hline$s_{7}(\mathrm{~mm})$ & 0.5 & 0.55 & 0.97 & 0.37 & 0.008 & 0.031 & 1.00 & 0.19 & 1.00 & 1.07 & 1.17 & 1.25 & 0.73 & 2.78 \\
\hline$s_{8}(\mathrm{~mm})$ & 0.1 & 0.58 & 1.08 & 0.44 & 0.011 & 0.027 & 0.97 & 0.28 & 1.05 & 1.07 & 1.15 & 1.25 & 0.69 & 3.22 \\
\hline $\bar{s}(\mathrm{~mm})$ & 0.07 & 0.53 & 1.04 & 0.38 & 0.01 & 0.028 & 1.04 & 0.24 & 1.03 & 1.02 & 1.16 & 1.24 & 0.73 & 2.99 \\
\hline
\end{tabular}

automatic acquisition instruments installed on pile TS1, $s_{5}$, $s_{6}, s_{7}$, and $s_{8}$ are the automatic acquisition instruments installed on pile TS2, $\bar{s}$ is the average of settlement under a certain load level. The settlement of two piles under each loading step is shown in Figure 5.

3.2. Axial Force of Pile Body Calculation. Axial force of the pile body is converted from the frequency of stress gauges on steel cage. The pile end resistance was approximately equal to the axial force calculated by using the lowest level stress gauge. The calculation process is as follows. According to the conversion formula of the stress gauges, the axial force of the steel bars can be obtained:

$$
N_{\mathrm{si}}=K\left(f_{i 2}-f_{i 0}^{2}\right)+B,
$$

where $N_{\mathrm{si}}$ is the axial force of the steel bars, $i$ is the number of stress gauges, $1 \sim 7$ from top to bottom. $K$ is the calibration coefficient; $f_{i 0}$ is the initial frequency of stress gauges, each 


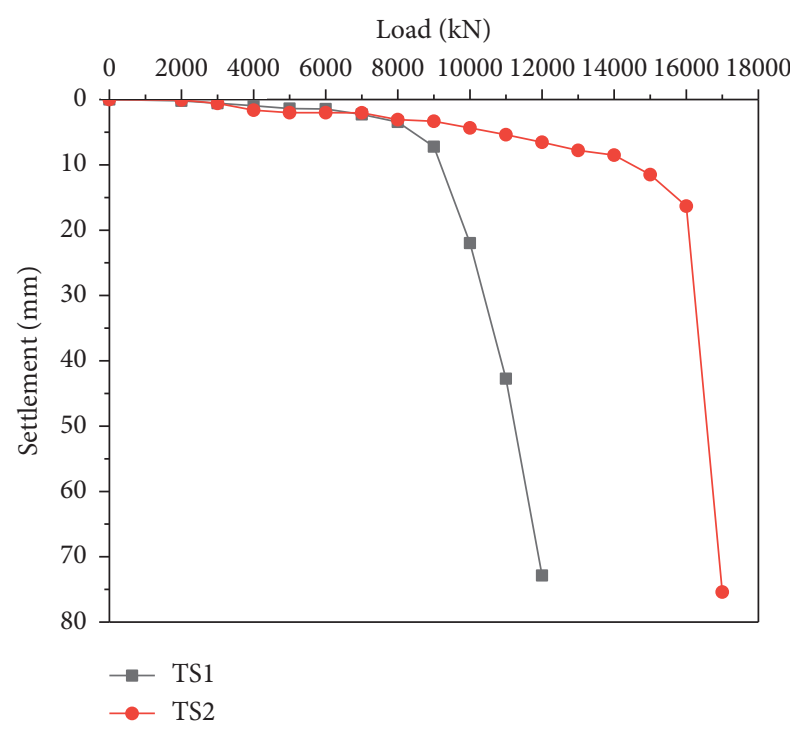

Figure 5: Settlement of TS1 pile and TS2 pile under each loading step.

stress gauge has an initial frequency $f_{i 0}$ when it leaves the factory; and $f_{i}$ is the frequency produced by using the sensor in the stress gauges under axial force. $B$ is the calculated correction value, which is 0 in this paper. So the strain of steel bar is as follows:

$$
\varepsilon_{\mathrm{si}}=\frac{N_{\mathrm{si}}}{E_{\mathrm{s}} A_{\mathrm{s}}}
$$

where $\varepsilon_{\mathrm{si}}$ is the strain of the steel bar; $E_{\mathrm{s}}$ is the elastic modulus of the steel bar, and $E_{\mathrm{s}}$ of steel bar in this test is $200 \mathrm{GPa}$; and $A_{\mathrm{s}}$ is the section area of steel bar, which is $0.0004909 \mathrm{~m}^{2}$ in this test. Since the reinforcement ratio is only $0.44 \%$, assuming that the same strain of concrete and steel bars in the same section as the stress gauge, the axial force of the pile body in section $i$ is as follows:

$$
Q_{\mathrm{ni}}=\left(E_{\mathrm{c}} A_{\mathrm{c}}+E_{\mathrm{s}} A_{\mathrm{s}}\right) \varepsilon_{\mathrm{si}},
$$

where $Q_{n i}$ is the axial force of the pile body under stage load $n$ and $\varepsilon_{\mathrm{si}}$ is the strain of concrete, $E_{\mathrm{c}}$ is the elastic modulus of concrete, which is $30 \mathrm{GPa}$ in this test. $A_{\mathrm{c}}$ is the section area of concrete; $\overline{\varepsilon_{\mathrm{si}}}$ is the average value of $\varepsilon_{\mathrm{si}}$. For example, when calculating the axial force of the pile TS2 under $3000 \mathrm{kN}$, the results are shown in Table 3 . And the axial force diagrams of TS1 and TS2 are shown in Figure 6.

3.3. Frictional Resistance Calculation. Frictional resistance along each pile was calculated by dividing the difference of two consecutive axial forces by the pile shaft area between the two stress gauges $[27,35]$, and side friction strength can be calculated by the following formula:

$$
q_{i}=\frac{Q_{i}-Q_{i-1}}{\pi d h_{i}},
$$

where $q_{i}$ is the side friction strength along the pile shaft, $d$ is the diameter of the pile, and $h_{i}$ is the height between adjacent sections. For example, the frictional resistance strength of TS2 pile under various loads is shown in Table 4. And the frictional resistance strength diagrams of TS1 and TS2 are shown in Figure 7.

\section{Layer-Wise Summation Method}

The total pile head displacement includes the compression of the foundation soil and the elastic compression of the pile body [33]; the compression of the foundation soil is calculated using the one-way layer summation method. The formulas are as follows:

$$
\begin{aligned}
& s=\psi \sum_{i=1}^{n} \frac{\sigma_{\mathrm{zi}}}{E_{\mathrm{si}}} \Delta z_{i}+s_{\mathrm{e}}, \\
& s_{\mathrm{e}}=\xi_{\mathrm{e}} \frac{\mathrm{Ql}}{E A_{\mathrm{ps}}},
\end{aligned}
$$

where $A_{\mathrm{ps}}$ is the cross section of the piles, $E_{\mathrm{si}}$ is the compression modulus of layer $i$ of the soil, and $E$ is the elastic modulus of the pile body. The reinforcement portion is low and the reinforcement ratio is only $0.44 \%$; therefore, the elastic modulus of concrete can be used for the pile body elastic modulus in general. The Code for Design of Concrete Structures (GB50010-2010) [36] was used; therefore, $E_{\mathrm{c}}$ of the $\mathrm{C} 30$ concrete is $30 \mathrm{GPa}$. $l$ is the length of the pile, $n$ is the number of soil layers, $Q$ is the pile top load, $s$ is the total pile head displacement, $s_{\mathrm{e}}$ is the elastic compression of the pile body, $\Delta z_{i}$ is the thickness of layer $i$ of the soil, $\sigma_{\mathrm{zi}}$ is the additional stress in layer $i$ of the soil calculated by the Mindlin-Geddes method, and $\xi_{\mathrm{e}}$ is the elastic compression coefficient of the pile body. The end-bearing pile $\xi_{\mathrm{e}}$ is 1.0. The friction pile $\xi_{\mathrm{e}}$ is 0.667 when $l / d \leq 30, \xi_{\mathrm{e}}$ is 0.5 when $l / d \geq 50$; a linear interpolation between the two is used; $\psi$ is the settlement empirical coefficient, which is 1 when there are no regional data.

Mindlin [37] proposed an analytical solution of the additional stress generated by the force at a point in the interior of a semiinfinite solid. Based on Mindlin's study, Geddes [38] deduced the formula for calculating the additional stress of a single pile for three kinds of pile side resistance distributions. Geddes' method divides the pile top load (Figure 8(a)) into three parts: one is the axial force (Figure 8(b)) transmitted along the pile body to the pile end; the other is the rectangular part (Figure 8(c)) of the pile side friction diagram after the pile side friction distribution diagram is split into rectangular and triangular parts; and the third is the triangular part (Figure $8(\mathrm{~d})$ ) of the pile side friction diagram. The outstanding advantage of Geddes' method is that it unifies the problem of pile-soil interaction with the concept of additional stress in the layer-wise summation method which is widely used in China. The load-sharing diagram of piles is shown in Figure 8.

Considering the influence of the pile diameter on the Mindlin solution, the additional stress at a calculation point is calculated as follows [34]: 
TABLe 3: Axial force calculation table of the pile TS2 body under $3000 \mathrm{kN}$.

\begin{tabular}{|c|c|c|c|c|c|c|c|c|}
\hline Depth (m) & Number $i$ & $K$ & $f_{i 0}$ & $\overline{f_{i}}$ & $N_{\mathrm{si}}$ & $\varepsilon_{\mathrm{si}}$ & $\overline{\overline{\varepsilon_{\mathrm{si}}}}$ & $Q_{2 i}$ \\
\hline 0.5 & $1(\mathrm{a})$ & 0.0002670 & 1356.7 & 1340.9 & -11.38009536 & -0.000115911 & & \\
\hline 0.5 & $1(\mathrm{~b})$ & 0.0002705 & 1472 & 1462.9 & -7.224403095 & $-7.35832 E-05$ & & \\
\hline 0.5 & $1(c)$ & 0.0002671 & 1491.2 & 1472.8 & -14.56699296 & -0.00014837 & -0.000112621 & -3996 \\
\hline 3.5 & $2(a)$ & 0.0002675 & 1444.5 & 1433.1 & -8.7752412 & $-8.93791 E-05$ & & \\
\hline 3.5 & 2(b) & 0.0002680 & 1420.2 & 1407 & -10.00150272 & -0.000101869 & & \\
\hline 3.5 & $2(c)$ & 0.0002677 & 1452.8 & 1442.4 & -8.060468416 & $-8.20989 E-05$ & $-9.11157 E-05$ & -3233 \\
\hline 7 & $3(a)$ & 0.0002679 & 1460.9 & 1449.2 & -9.121504743 & $-9.29059 E-05$ & & \\
\hline 7 & $3(\mathrm{~b})$ & 0.0002681 & 1443.5 & 1431.1 & -9.556435224 & $-9.73359 E-05$ & & \\
\hline 7 & $3(c)$ & 0.0002667 & 1475 & 1466.1 & -6.981083193 & $-7.11049 E-05$ & $-8.71156 E-05$ & -3091 \\
\hline 11.5 & $4(\mathrm{a})$ & 0.0002671 & 1384.9 & 1373.7 & -8.252407072 & $-8.40539 E-05$ & & \\
\hline 11.5 & $4(\mathrm{~b})$ & 0.0002779 & 1465.1 & 1454.4 & -8.681220835 & $-8.84215 E-05$ & & \\
\hline 11.5 & $4(c)$ & 0.0002665 & 1401.8 & 1389.3 & -9.297851875 & $-9.47021 E-05$ & $-8.90591 E-05$ & -3160 \\
\hline 16 & $5(a)$ & 0.0002668 & 1474 & 1458.9 & -11.81571557 & -0.000120347 & & \\
\hline 16 & $5(\mathrm{~b})$ & 0.0002669 & 1430.5 & 1412 & -14.03527013 & -0.000142954 & & \\
\hline 16 & $5(c)$ & 0.0002682 & 1393.5 & 1384.5 & -6.7055364 & $-6.82984 E-05$ & -0.000110533 & -3922 \\
\hline 20.5 & $6(a)$ & 0.0002688 & 1425.3 & 1417.9 & -5.655465984 & $-5.7603 E-05$ & & \\
\hline 20.5 & 6(b) & 0.0002665 & 1439.5 & 1423.2 & -12.43542566 & -0.000126659 & & \\
\hline 20.5 & $6(c)$ & 0.0002680 & 1479.3 & 1474.3 & -3.957824 & $-4.03119 E-05$ & $-7.48581 E-05$ & -2656 \\
\hline 24.5 & $7(\mathrm{a})$ & 0.0002669 & 1471.1 & 1465.3 & -4.545605928 & $-4.62987 E-05$ & & \\
\hline 24.5 & $7(b)$ & 0.0002672 & 1430.4 & 1424.9 & -4.19614888 & $-4.27393 E-05$ & & \\
\hline 24.5 & $7(\mathrm{c})$ & 0.0002675 & 1467.7 & 1464.9 & -2.1965174 & $-2.23724 E-05$ & $-3.71368 E-05$ & -1317 \\
\hline
\end{tabular}

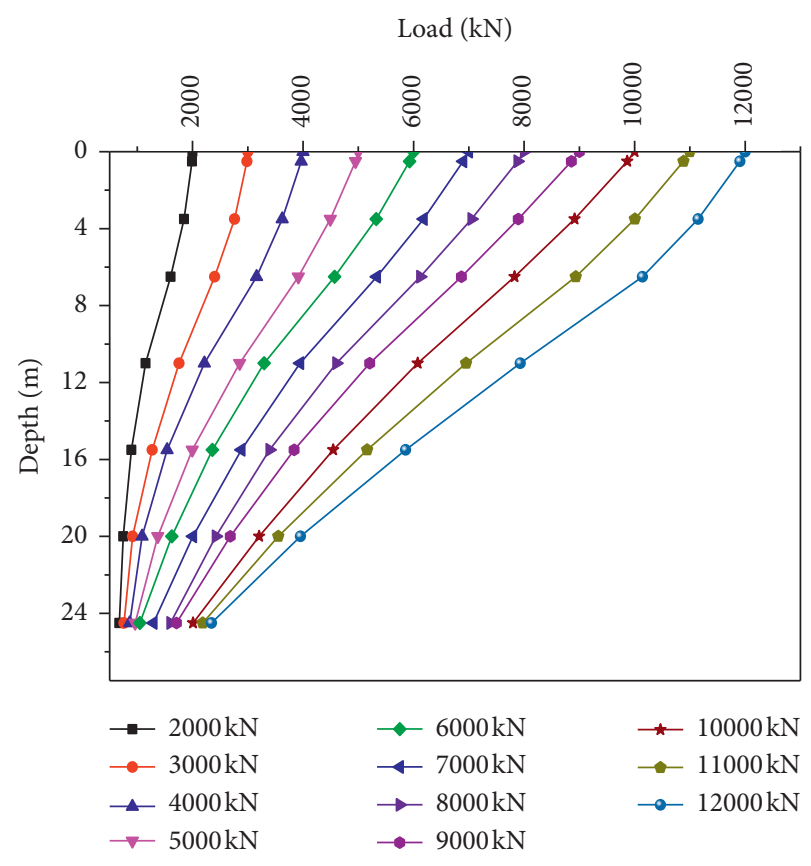

(a)
Load $(\mathrm{kN})$

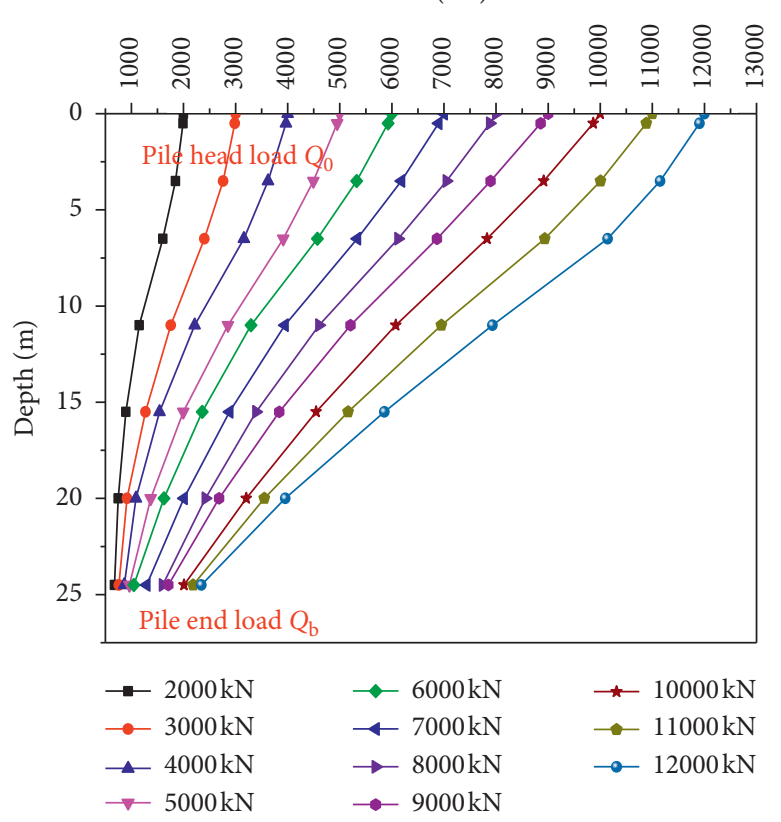

(b)

FIgURE 6: The axial force of piles (a) TS1 and (b) TS2.

$$
\begin{aligned}
\sigma_{\mathrm{zi}} & =\sigma_{\mathrm{zpi}}+\sigma_{\mathrm{zsri}}+\sigma_{\mathrm{zsti}}, \\
\sigma_{\mathrm{zpi}} & =\frac{\alpha Q}{l^{2}} I_{\mathrm{pi}}, \\
\sigma_{\mathrm{zsri}} & =\frac{\beta Q}{l^{2}} I_{\mathrm{sri}},
\end{aligned}
$$

$$
\sigma_{\mathrm{zsti}}=\frac{(1-\alpha-\beta) Q}{l^{2}} I_{\mathrm{sti}}
$$

where $I_{\mathrm{pi}}, I_{\text {sri }}$, and $I_{\text {sti }}$ are the vertical stress coefficients of any point in the soil under pile end load, load shared by rectangular-shaped friction resistance, and load shared by triangular-shaped friction resistance, respectively; this was 


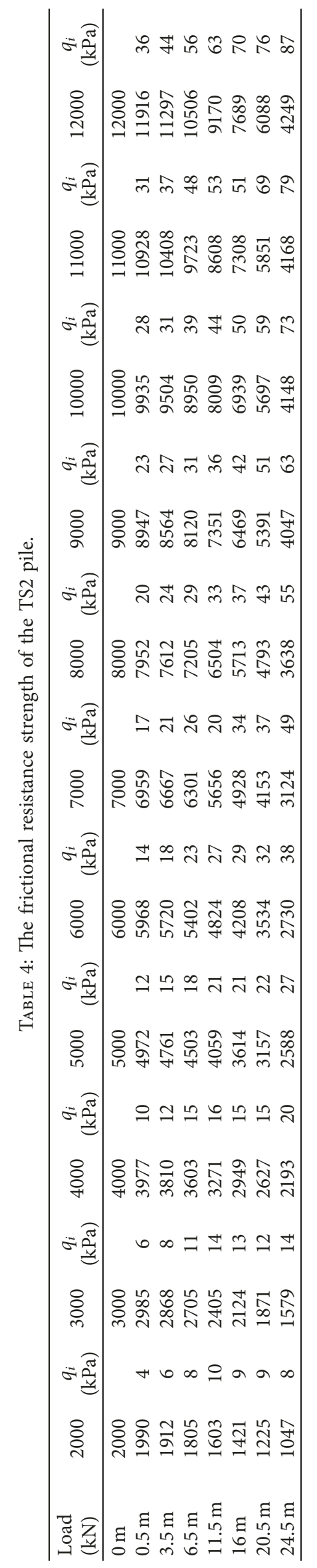




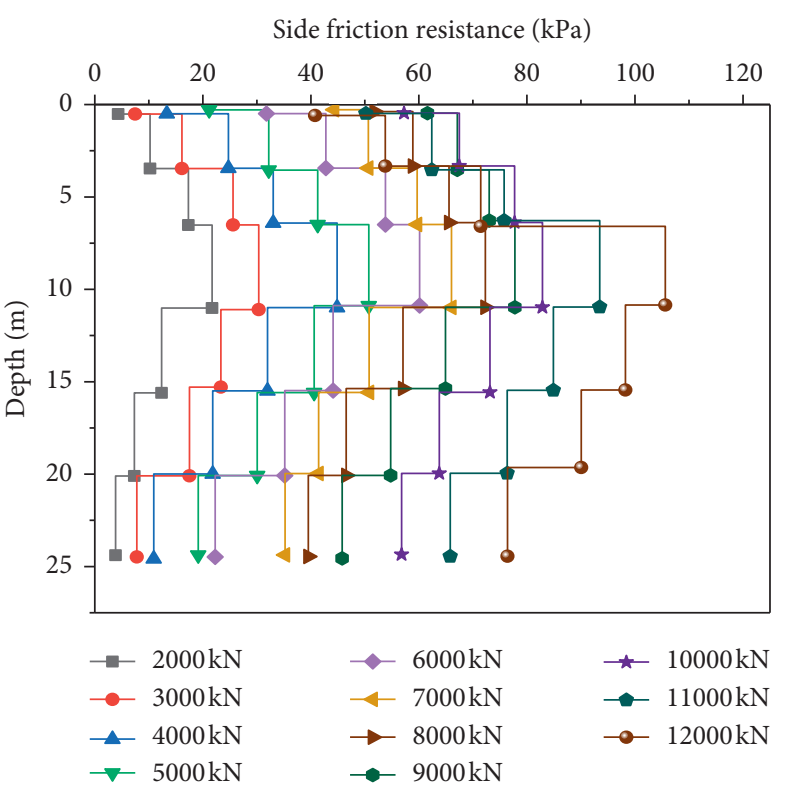

(a)

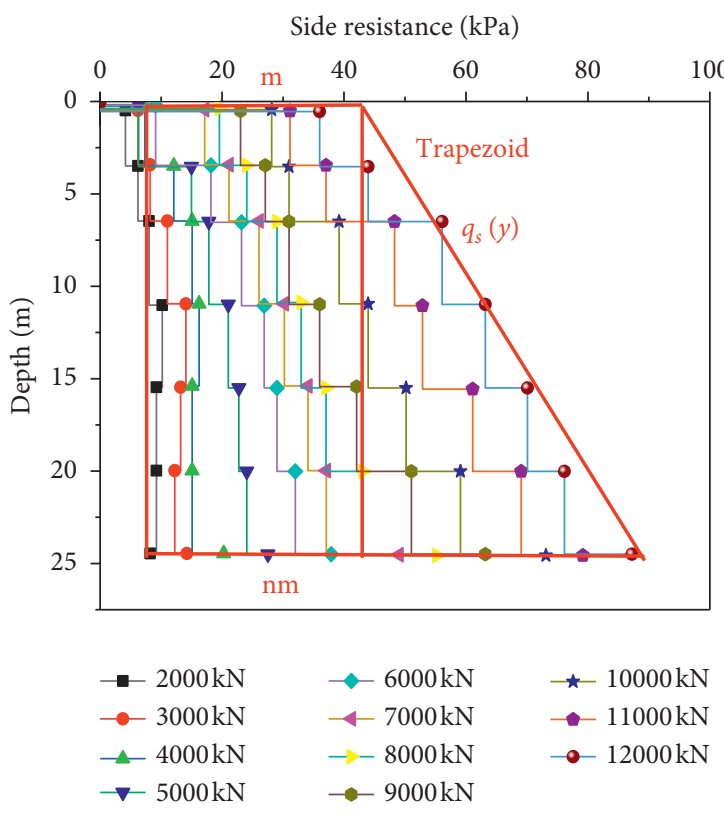

(b)

FIGURE 7: The frictional resistance strength diagram of (a) TS1 and (b) TS2 along the pile shaft.

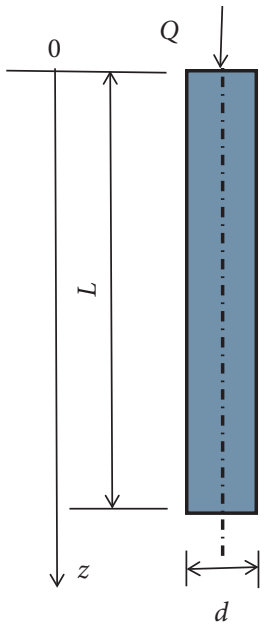

(a)

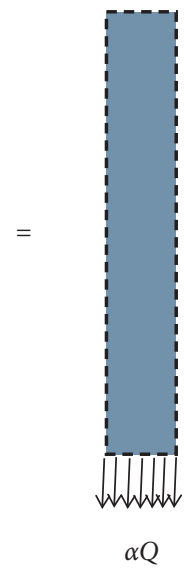

(b)

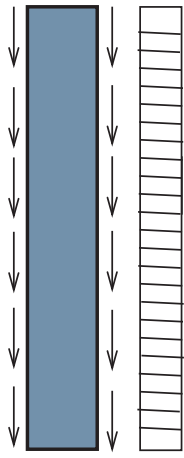

$\beta Q$

(c)

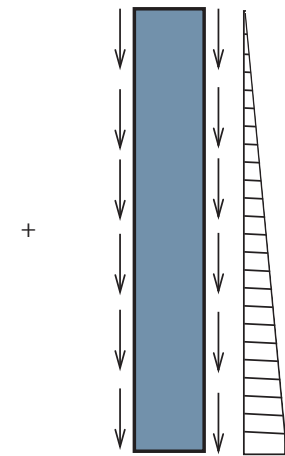

$(1-\alpha-\beta) Q$

(d)

FIGURE 8: Load-sharing diagram of piles.

determined based on the data in Appendix F of the code [32]. $\sigma_{\text {zpi }}$ is the additional stress caused by the pile end resistance at the calculation point; $\sigma_{\text {zsri }}$ and $\sigma_{\text {zsti }}$ are the additional stress at the calculation point when the pile side resistance is rectangular- or triangular-shaped, respectively; and $\alpha$ is the pile end resistance ratio, which is the average of the ratio of the axial force at the pile end to the top load of the pile under different loads in the axial force diagram of the pile. $\beta$ is the side resistance ratio, which is the ratio of the area of the rectangular part to the top load of the pile in the diagram of the side resistance distribution.

In equations (6)-(11), $A_{\mathrm{p} s}, E, l$, and $\Delta z_{i}$ are assumed at the design stage; $\alpha$ and $\beta$ are obtained from the pile testing data; and $\sigma_{\mathrm{zi}}$ is calculated using equations (8)-(11). The crucial parameters $\xi_{\mathrm{e}}, E_{\mathrm{si}}$, and $\psi$ in the layer-wise summation method depend on the complexity of the soil and are commonly established using regional data; therefore, these three parameters will be optimized using the Wuqi-Dingbian expressway test data.

\section{Parameters Calculation and Optimization}

In this test, the pile head settlement of the nongrouting pile TS1 was calculated using the layer-wise summation method. However, when this method is used to calculate the settlement of the postgrouting pile TS2, the values of $\xi_{\mathrm{e}}, E_{\mathrm{si}}$, and $\psi$ need to be optimized separately as follows. 
5.1. Modified Elastic Compression Coefficient. The pile body compression accounts for a large proportion of the total settlement of pile, so the pile body compression is very important in calculating the settlement of pile [33]. During the calculation, different end resistance ratios and side resistance distributions will affect the elastic compression of the pile body [39]. Especially after grouting, the elastic compression coefficient changes due to changes in the side resistance distribution and the end resistance ratio. However, the specific values given in the code [32] do not take into account the effect of postgrouting. Therefore, the elastic compression $s_{\mathrm{e}}(y)$ of the postgrouting pile needs to be recalculated, and this paper proposes a method to clarify the elastic compression coefficient using the Mindlin-Geddes method. And the calculation model of pile compression is shown in Figure 9.

Assuming that $Q_{0}$ is the pile head load and $q_{\mathrm{s}}(y)$ is the side resistance at a given depth $y$, the axial force $Q_{y}$ at depth $y$ can be defined using the following equation:

$$
Q_{y}=Q_{0}-\pi d \int_{0}^{y} q_{\mathrm{s}}(y) d y .
$$

Assuming that the elastic compression of the pile is linearly elastic, the unit elastic compression $d s_{\mathrm{e}}$ of the $d y$ segment at depth $y$ can be described as

$$
d s_{\mathrm{e}}=\frac{Q_{y}}{A_{\mathrm{ps}} E} d y .
$$

By integrating (13), the elastic compression of the pile body above depth $y$ is obtained:

$$
s_{\mathrm{e}}(y)=\int_{0}^{y} \frac{\mathrm{Q}_{y}}{A_{\mathrm{ps}} E} d y=\frac{1}{A_{\mathrm{ps}} E} \int_{0}^{y} \mathrm{Q}_{y} d y .
$$

Therefore, the elastic compression $s_{\mathrm{e}}$ of the whole pile is defined as

$$
s_{\mathrm{e}}=\frac{1}{A_{\mathrm{ps}} E} \int_{0}^{l}\left[Q_{0}-\pi d \int_{0}^{l} q_{\mathrm{s}}(y) d y\right] d y .
$$

Axial force and side resistance of pile TS2 under different loads obtained from field test are shown in Figures 6(b) and $7(b) . \alpha$ is the average ratio of pile end load to pile head load under the same load. $\beta$ is the ratio of the area of the rectangular part to the pile head load in the diagram of side resistance distribution. The shape of the side resistance distribution is similar to a trapezoid; thus, based on the Mindlin-Geddes method, this paper only considered the case when $q_{\mathrm{s}}(y)$ is a trapezoid. The formula $Q_{\mathrm{b}}=\alpha Q_{0}$ can be obtained by assuming $\alpha$ is the end resistance ratio and $Q_{\mathrm{b}}$ is the pile end load. And assuming that the pile head side resistance is $m$, the ratio of pile head side resistance to pile bottom side resistance is $1: n$, so the pile end side resistance is $n m$, as shown in Figure 7(b). The side resistance of the whole pile can be written as

$$
\int_{0}^{l} q_{s}(y) d y=\frac{(1-\alpha) Q_{0}}{\pi d}=\frac{m(1+n) \times l}{2} .
$$

The value of $m$ is derived from (16):

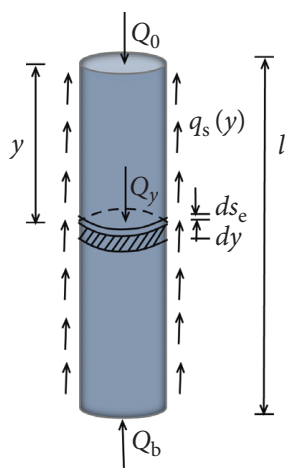

Figure 9: Calculation model of pile compression.

$$
m=\frac{2(1-\alpha) Q_{0}}{(1+n) \pi d l} .
$$

Figure 7(b) shows that the linear expression of $q_{\mathrm{s}}(y)$ is

$$
q_{\mathrm{s}}(y)=\frac{m(n-1) y}{l}+m \text {. }
$$

By substituting equation (17) into (18), $q_{\mathrm{s}}(y)$ in the shape of a trapezoid becomes

$$
q_{\mathrm{s}}(y)=\frac{2(n-1)(1-\alpha) Q_{0}}{\pi d l(1+n)} \cdot \frac{y}{l}+\frac{2(1-\alpha) Q_{0}}{\pi d l(1+n)} .
$$

By substituting (19) into (15), $s_{\mathrm{e}}$ can be written as

$$
s_{\mathrm{e}}=\frac{Q_{0} l}{A_{\mathrm{ps}} E}-\frac{(n+2)(1-\alpha) Q_{0} l}{3(1+n) A_{\mathrm{ps}} E}=\left(\frac{n+2}{3+3 n} \alpha+\frac{2 n+1}{3+3 n}\right) \frac{Q_{0} l}{A_{\mathrm{ps}} E} \text {. }
$$

In order to remain consistent with $\xi_{\mathrm{e}}$ in the code [32], a modified compression coefficient $\xi_{\mathrm{e}}^{\prime}$ is proposed in this study; therefore, $s_{\mathrm{e}}$ can be written as

$$
s_{\mathrm{e}}=\xi^{\prime} \frac{Q_{0} l}{A_{\mathrm{ps}} E}=f(\alpha) \frac{Q_{0} l}{A_{\mathrm{ps}} E} .
$$

Therefore, the relationship between $\xi_{\mathrm{e}}^{\prime}$ and $\alpha$ can be defined by the following equation:

$$
\xi_{\mathrm{e}}^{\prime}=\frac{n+2}{3+3 n} \alpha+\frac{2 n+1}{3+3 n} .
$$

\subsection{Changes in the End Resistance Ratio and Pile Diameter}

5.2.1. Change in the End Resistance Ratio. The cement slurry exerts functions on the loess soil at the bottom of the pile at the same time during grouting, including penetration, compaction, and cleavage, especially compaction and cleavage. The loose soil or cracks are cemented to a cement mixture with certain strength by penetration, compaction, and cleavage as the cement slurry is applied under pressure, which effectively improves the end resistance and increases the end resistance ratio [40]. In order to determine the change in $\alpha$ after grouting, the end resistance of the piles TS1 and TS2 under different loads is determined, as shown in 
Figure 10(a). It can be seen that the load transferred from the top of the pile to the pile end is significantly larger for TS2 (postgrouting) than for TS1 (nongrouting) under the same load, that is, $\alpha$ is increased.

The ratio of the increase in the end resistance ratio of pile TS2 to that of pile TS1 under different loads is expressed as the improvement coefficient of the end resistance ratio $\varepsilon$, which is expressed in percentage. We compared our results with those of postgrouting tests carried out in two other projects in this region with the same soil layers and the same piles and measured using the same test method by the engineering staff. The statistical results are shown in Figure 10(b). It can be seen that $\alpha$ is higher after grouting in most cases; that is, the load transferred to the pile end is higher and the coefficient $\varepsilon$ is in the range of $40 \sim 120 \%$; therefore, the average value of $80 \%$ is used for the calculation.

The ratio of the TS1 pile end resistance to the pile top load is about 0.2 (Figure $10(\mathrm{a})$ ), that is, $\alpha$ is 0.2 ; therefore TS1 is the friction pile and $l / d<30$; the corresponding $\xi_{\mathrm{e}}$ determined based on the code [32] is 0.667 . It can be seen from Figure 7 (b) that $1: n$ is about $1: 2$ and $\alpha$ after grouting is calculated as 0.36 by multiplying 0.2 and 1.8 ; therefore, $\xi_{\mathrm{e}}^{\prime}$ is 0.716 according to equation (22). The elastic compression coefficient is higher after the revision, indicating a higher compression of the pile body.

5.2.2. Change in the Pile Diameter. Due to the high grouting pressure at the pile end and the low permeability of the foundation soil, part of the serous fluid moves upward in the gap between the pile body and the soil surrounding the pile, forming a layer of cement slurry around the pile [40]. In this study, the Mindlin solution, which considers the influence of the pile diameter, is used to calculate the additional stress; therefore, the stress coefficient changes with the change in the pile diameter, which affects the calculation results [41]. Therefore, the change in the pile diameter has to be revised.

Taking pile TS2 as an example, mud spillover (Figure 11(a)) occurred at the top of the pile during the last stage of grouting. The soil was excavated along the pile body after grouting, and a vertical cement shell (Figure 11(b)) was found around the pile. Therefore, it was assumed that the cement slurry between the soil and the pile interface seeped to the top of the pile along the pile/soil interface. The vertical distance between the cement shell and the pile body was measured at two locations at four different depths along the pile. The statistical results are shown in Table 5. For simplified calculation, an average value of $1575 \mathrm{~mm}$ was taken as the diameter of the pile after grouting. Therefore, the diameter of the pile TS2 after grouting was 1.05 times larger than that of the pile before grouting, as shown in Figure 11(c).

5.2.3. Compression Modulus. The compression modulus is a vital parameter when using the layer-wise summation method to calculate the settlement of the foundation soil. In most cases, the settlement of the foundation soil is only calculated by using the compression modulus $E_{s, 1-2}$ measured in the pressure range of $100 \mathrm{kPa} 200 \mathrm{kPa}$. However, the level of gravity stress and additional stress far exceeds $200 \mathrm{kPa}$ in practical applications; therefore, the influence of gravity stress on the compression modulus should be considered when calculating the settlement [42].

Drilling was conducted in five engineering areas on the Wuqi-Dingbian expressway, and the soil was sampled during the test. Five core samples were obtained, and their unit weights $\gamma_{i}$ ( $i$ is the serial numbers of the soil samples, $i=1 \sim 5$ ) were measured indoors. The depth $z_{j}$ ( $j$ is the serial number of the calculation point from top to bottom, $j=1 \sim 5$ ) of the calculation point of the soil sample at $P_{1}=200 \mathrm{kPa}$, $P_{2}=300 \mathrm{kPa}, P_{3}=400 \mathrm{kPa}, P_{4}=500 \mathrm{kPa}$, and $P_{5}=600 \mathrm{kPa}$ is calculated, respectively, by $\gamma_{i}$ using the formula $z_{j}=P_{j} / \gamma$. The calculation results are shown in Figure 12.

The compression test was applied to the five core samples to obtain $E_{s, z}$ and $E_{s, 1-2}$ of the soil samples at 25 positions. The reliability of the linear model that was used to describe the relationship between the ratio of $E_{s, z}$ and $E_{s, 1-2}$ and $P$ is assessed, as shown in Figure 13(a). This linear relationship can be described using the following equations:

$$
\begin{aligned}
\frac{E_{s, z}}{E_{s, 1-2}} & =0.00463 P+0.1721 \\
E_{s, z} & =(0.00463 P+0.1721) E_{s, 1-2} \\
E_{s, z} & =(0.00463 \gamma h+0.1721) E_{s, 1-2}
\end{aligned}
$$

where $h$ is the soil depth, $P$ is the soil gravity stress, and $\gamma$ is the unit weight of the soil.

Equation (25) is highly reliable $\left(R^{2}>0.91\right)$. Assuming that $\gamma=18.5 \mathrm{kN} / \mathrm{m}^{3}$, as can be seen from equation (25), $E_{s, z}$ is about equal to $E_{s, 1-2}$ when $h=10 \mathrm{~m}$. Therefore, $E_{s, z}$ within $10 \mathrm{~m}$ can take $E_{s, 1-2}$, but when the depth is more than $10 \mathrm{~m}$, $E_{s, z}$ continues to increase with the increase in $P$. As shown in Figure 13(a), $E_{s, z}$ is already two times larger than $E_{s, 1-2}$ when $P=380 \mathrm{kPa}$; therefore, the values of $E_{s, 1-2}$ are no longer suitable. Therefore, $E_{s, z}$ within the range of compression can be calculated by using equation (25).

In addition, the double bridge cone penetration test was performed near the drilling points in the five engineering areas. Another method for calculating $E_{s, z}$ is obtained by analyzing the relationship between the cone resistance $q_{\mathrm{c}}$ measured at the same depth as the 25 positions and $E_{s, z}$, as shown in Figure 13(b).

The resulting expression for $q_{\mathrm{c}}$ and $E_{s, z}$ is given by the following equation:

$$
E_{s, z}=2.631 q_{c}+7.177 \text {. }
$$

Equation (26) is highly reliable $\left(R^{2}>0.87\right)$; therefore, there is a significant correlation between $q_{\mathrm{c}}$ and $E_{s, z}$. In order to verify the rationality of equation (26), the values of $E_{s, z}$ obtained from the abovementioned two methods were compared to ensure that they were consistent with the result in Figure 14. Therefore, $E_{s, z}$ at any depth can be calculated using the two methods (equations (25) and (26)) when calculating the settlement in the loess area of northern Shaanxi, China. 


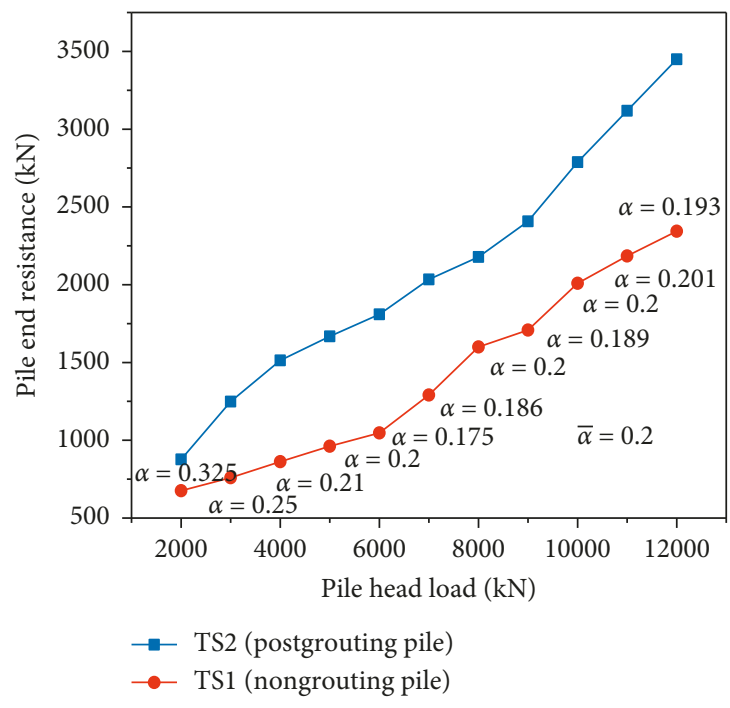

(a)

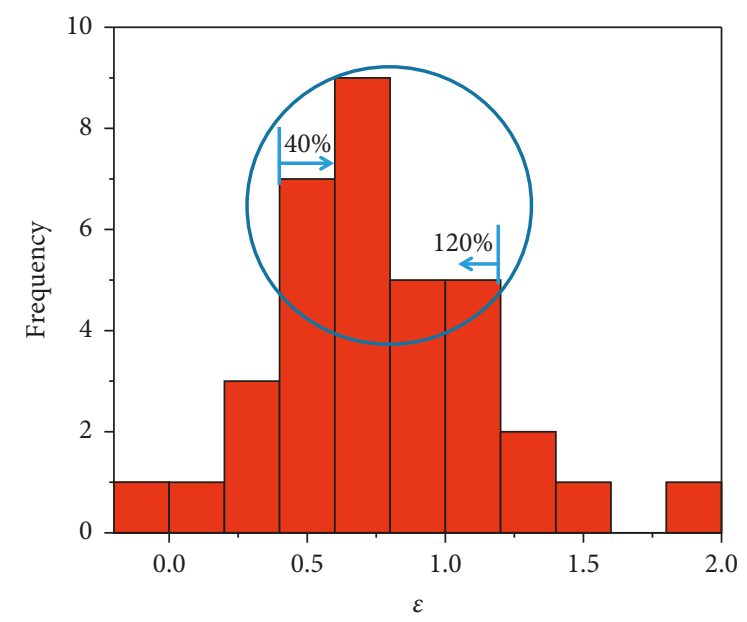

(b)

FIgURE 10: (a) End resistance ratio of piles TS1 and TS2 under different loads; (b) statistical chart of the end resistance ratio improvement coefficient $\varepsilon$ after grouting.

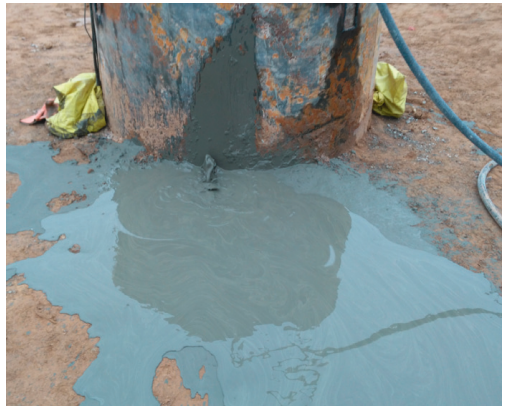

(a)

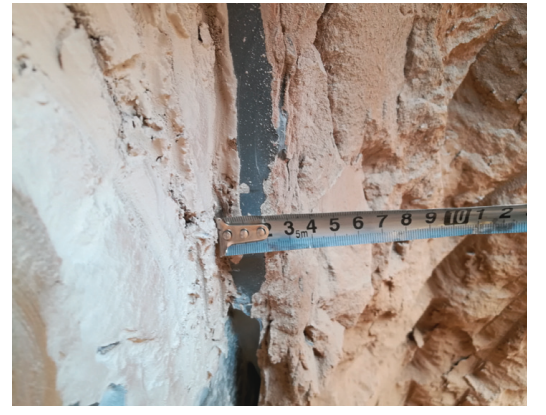

(b)

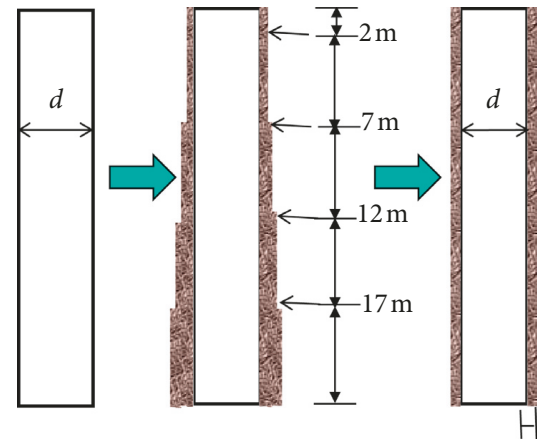

$37.5 \mathrm{~mm}$

(c)

Figure 11: (a) Mud Spillover. (b) Cement shell. (c) Simplified diagram of slurry return.

TABLE 5: Vertical distance between cement shell and pile body.

\begin{tabular}{|c|c|c|c|c|c|}
\hline \multicolumn{2}{|c|}{ Distance from the ground } & $2 \mathrm{~m}$ & $7 \mathrm{~m}$ & $12 \mathrm{~m}$ & $17 \mathrm{~m}$ \\
\hline & Location 1 & 21.9 & 29.0 & 36.3 & 50.1 \\
\hline Vertical distance $(\mathrm{mm})$ & $\begin{array}{c}\text { Location } 2 \\
\text { Average }\end{array}$ & 25.1 & 32.3 & 38.7 & 62.6 \\
\hline
\end{tabular}

The fitted equations (25) and (26) can be used on the one hand to revise $E_{s, z}$ obtained from the compression test so that an accurate value of $E_{s, z}$ of the loess in this area can be obtained; on the other hand, the workload associated with field investigations and indoor compression tests are reduced, resulting in time and cost savings.

Zhou et al. [43] found that the soil around the grouting point was continuously compressed and the porosity gradually decreased during the grouting process, resulting in the change in $E_{s, z}$. The compression of the soil was most apparent in the range of $0.5 \mathrm{~m}$ around the grouting point. Therefore, the compression modulus improvement coefficient $\phi$ is introduced to revise $E_{s, z}$ at the end of the postgrouting pile.

In order to study the compression modulus improvement coefficient $\phi$ of soil around the grouting point, formula $P=\gamma h$ can be used to calculate the soil gravity stress $P$ in the range of $1 \mathrm{~m}$ at pile tip, in which $\gamma$ is $18.5 \mathrm{~g} / \mathrm{cm}^{3}$ and $h$ are $24.5 \mathrm{~m}, 24.75 \mathrm{~m}, 25 \mathrm{~m}, 25.25 \mathrm{~m}, 25.5 \mathrm{~m}, 25.75 \mathrm{~m}, 26 \mathrm{~m}$, $26.25 \mathrm{~m}$, and $26.5 \mathrm{~m}$, respectively. Therefore, the soil gravity stress $P$ at different depths near the grouting point are 43.33 MPa, 45.79 MPa, 46.25 MPa, 46.71 MPa, 47.18 MPa, $47.64 \mathrm{MPa}, 48.1 \mathrm{MPa}, 48.56 \mathrm{MPa}$, and $49.03 \mathrm{MPa}$. Then, $E_{s, z}$ can be calculated according to formula (24). We compared 


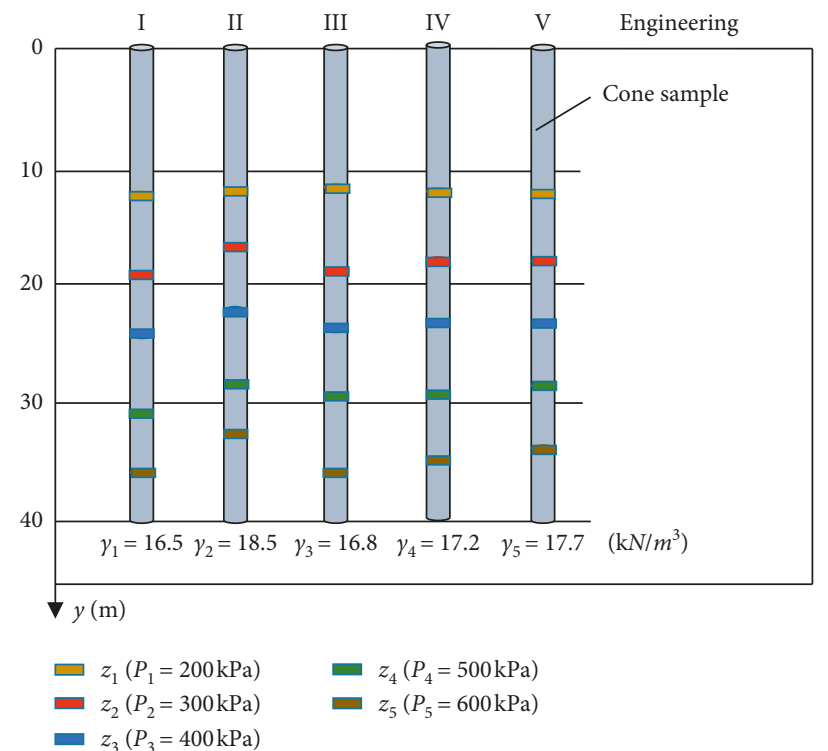

Figure 12: Depth of the calculation points for each core sample.

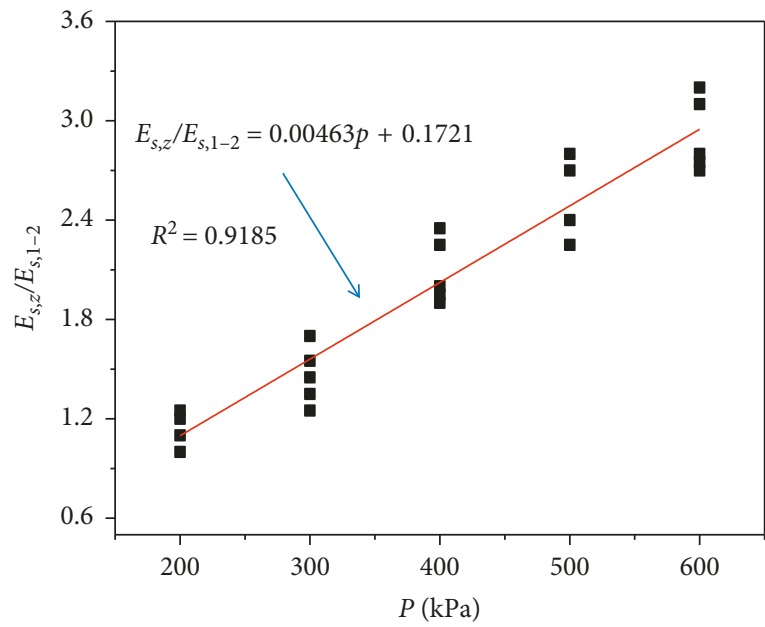

(a)

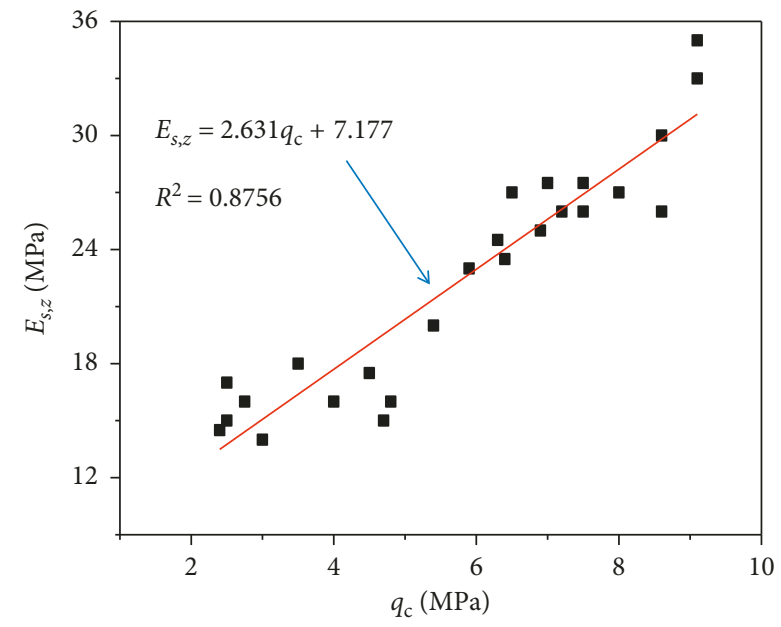

(b)

FIGURE 13: (a) The ratio of $E_{s, z}$ to $E_{s, 1-2}$ under different gravity stress. (b) Relationship between $q_{\mathrm{c}}$ and $E_{s, z}$.

$E_{s, z}$ calculated by $P$ with the measured value of $E_{s, z}$ after grouting; the reference value of $\phi$ in this area is given in Table 6 after inverse calculation. The modified compression modulus $E_{s}^{\prime}$ of the soil layers can be obtained by multiplying the compression modulus of the soil layers obtained from the abovementioned two methods and the corresponding improvement coefficient. The formula is written as follows:

$$
E_{\mathrm{s}}^{\prime}=\varphi E_{\mathrm{s}}
$$

5.3. Settlement Empirical Coefficient. The settlement empirical coefficient $\psi$ in equation (6) is a vital parameter for calculating the pile settlement using the layer-wise summation method. The accuracy of the settlement empirical coefficient is very important because it is a correction coefficient. It was stated in the latest pile foundation code [32] that the settlement empirical coefficient should be 1.0 when there are no regional data. There will be a large discrepancy between the calculation results and measured results of the pile settlement when 1.0 is used directly without considering the influence of the regional soil properties. In this test, the soil layer is divided into two layers. $1.8 \mathrm{~m}$ below the ground is loessial loess and the depth of old loess in the lower layer is more than $50 \mathrm{~m}$. Because the thickness of loessial loess is relatively small compared with that of old loess, the soil layer can be simplified to a single old loess layer. Therefore, the appropriate settlement empirical 


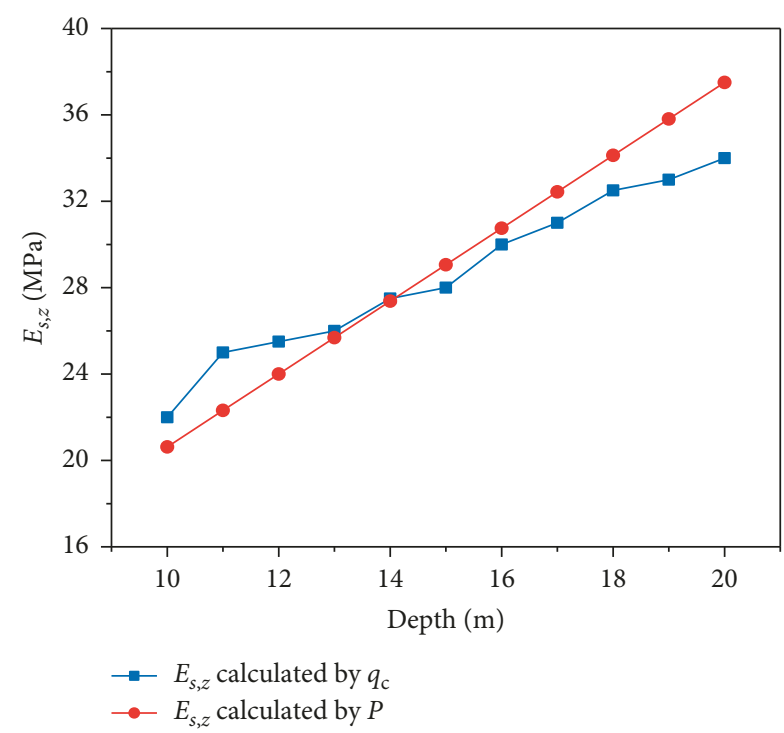

Figure 14: Comparison of the two methods.

TABLE 6: Reference value of $\phi$ for different distance ranges from the pile end.

\begin{tabular}{lcccc}
\hline $\begin{array}{l}\text { Distance from } \\
\text { pile end }(\mathrm{m})\end{array}$ & $0 \sim 0.25 \mathrm{~m}$ & $0.25 \sim 0.75 \mathrm{~m}$ & $0.75 \sim 1.25 \mathrm{~m}$ & $>1.25 \mathrm{~m}$ \\
\hline$\Phi$ & $7.5 \sim 20$ & $2.5 \sim 10.5$ & $1.2 \sim 5.5$ & 1 \\
\hline
\end{tabular}

coefficients in this area were obtained by comparing the settlement calculation results with the measured results for different settlement empirical coefficients.

Equations (6)-(11), (22), (24), and (27) are used to calculate the settlement of TS1 for the settlement empirical coefficient $\psi$ values of $0.2,0.3,0.4,0.5,0.6,0.7,0.8$, and 0.9 . The results are shown in Figure 15.

In order to determine the ultimate bearing capacity of TS1 pile, $P \sim S$ curve and $\log P \sim \log S$ curve are shown in Figure 16, and three methods for determining the vertical ultimate bearing capacity are presented as follows: (1) the corresponding load of the point where the $P \sim S$ curve (Figure 16(a)) falls sharply can be regarded as the vertical ultimate bearing capacity of the TS1 pile. (2) The load corresponding to the most obvious turning point in $\log P \sim \log S$ curve (Figure 16(b)) is selected as the ultimate bearing capacity of the TS1 pile. (3) Under a certain level of load, the settlement of the pile top is five times larger than that under the former level of load. The value of the former level of load is taken as the ultimate bearing capacity of the pile. The settlement under $10000 \mathrm{kN}$ load is about five times that under $9000 \mathrm{kN}$ load. Therefore by using the above three methods, the bearing capacity of the TS1 pile is $9000 \mathrm{kN}$.

A comparison of the measured values and calculated values of the pile settlement for different empirical coefficients under various loads indicates that when the settlement of TS1 pile reaches its ultimate bearing capacity of $9000 \mathrm{kN}$, the measured curve is close to the curve when the settlement empirical coefficient $\psi$ is 0.3 ; therefore, $\psi$ should be 0.4 to meet the requirements of safety and economy.

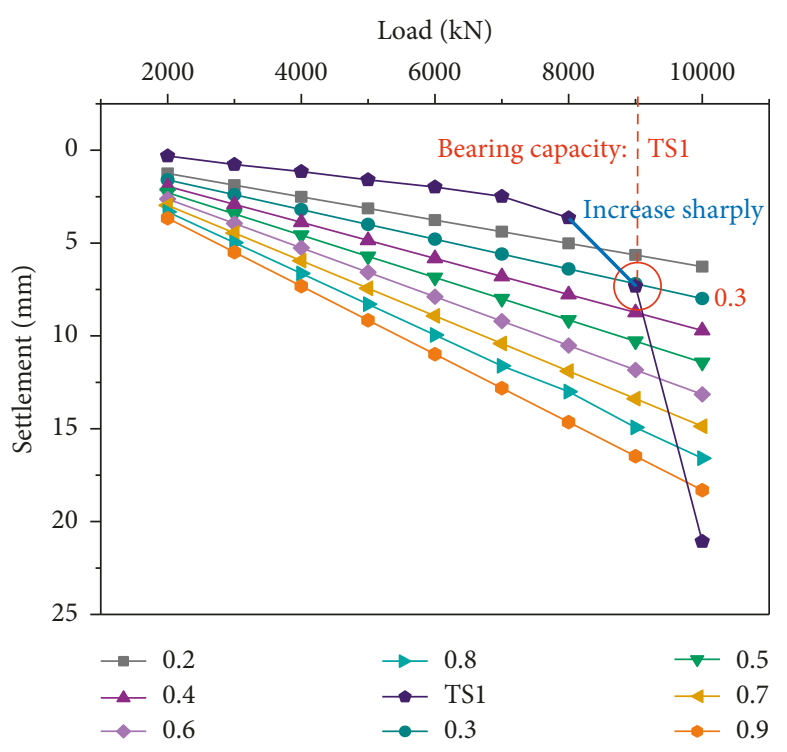

FIgURE 15: Settlement values for different empirical coefficients $\psi$

\section{Example Calculation}

We use the pile TS2 as an example and calculate the settlement of the postgrouting pile using the layer-wise summation method after parametric optimization. The pile diameter is 1.05 times larger than the original pile diameter, which is $1.575 \mathrm{~m}$, due to the upward seepage of the slurry. The distribution pattern of the pile side resistance is trapezoid-shaped, and the ratio of the side resistance of the pile top and pile bottom is $1: 2 . \alpha$ after grouting is $0.36, \beta$ is 0.43 , $\xi_{\mathrm{e}}^{\prime}$ is 0.716 , and $\psi$ is 0.4 .

For example, the settlement of the pile TS2 at $9000 \mathrm{kN}$ is obtained using equations (6)-(11), (20), (22), (24), and (27); the calculation results are shown in Table 7.

The compression of the pile body is

$s_{\mathrm{e}}=\xi_{\mathrm{e}} \frac{\mathrm{Ql}}{E A_{\mathrm{ps}}}=0.716 \times \frac{9000 \times 10^{3} \times 25}{3.0 \times 10^{10} \times \pi \times(1.575 / 2)^{2}}=2.758 \mathrm{~mm}$.

The total pile head settlement at $9000 \mathrm{kN}$ is calculated as

$$
s=2.758+3.325=6.083 \mathrm{~mm} .
$$

The total settlement for all loads after grouting is obtained using the abovementioned method and is compared with the calculated settlement without considering the grouting effect and the actual settlement (Figure 17).

As shown in Figure 17, the actual settlement of the TS2 pile is $8.7 \mathrm{~mm}$ when the pile reaches the ultimate bearing capacity of $14000 \mathrm{kN}$. The calculated settlement considering the grouting effect and without considering the grouting effect is $12.3 \mathrm{~mm}$ and $14.2 \mathrm{~mm}$, respectively. Therefore, it can be concluded as follows: (1) the calculated settlement is less when the postgrouting effect is considered; therefore, the postgrouting method at the pile end reduces the amount of settlement. (2) The actual settlement prior to destruction is less than the calculated settlement and the actual settlement 


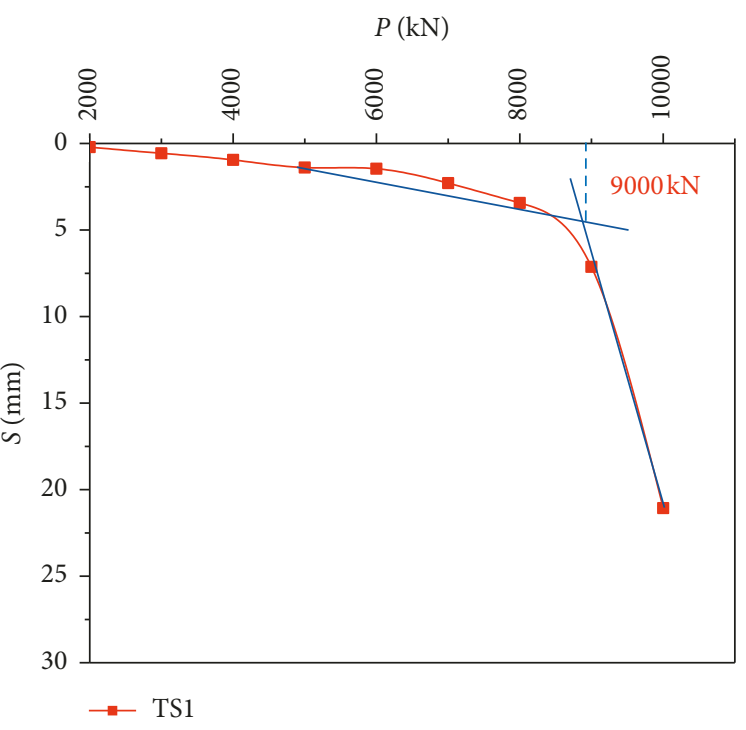

(a)

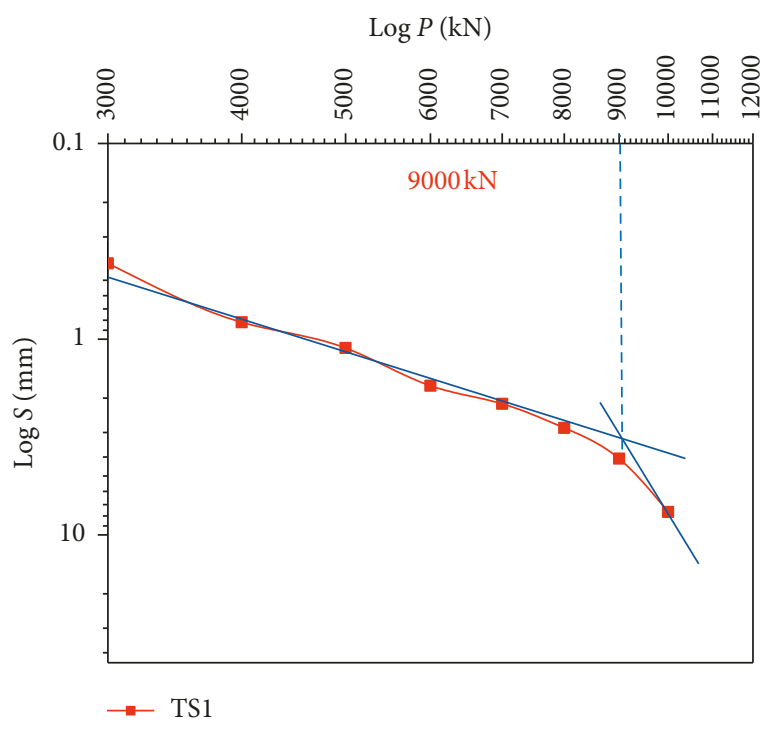

(b)

Figure 16: (a) $P \sim S$ curve; (b) $\log P \sim \log S$ curve.

TABLE 7: Calculated settlement of the postgrouting pile foundation.

\begin{tabular}{|c|c|c|c|c|c|c|c|c|c|c|}
\hline Layer number $i$ & Thickness (m) & Depth $(\mathrm{m})$ & $E_{s, z}(\mathrm{MPa})$ & $I_{\mathrm{pi}}$ & $I_{\text {sri }}$ & $I_{\text {sri }}$ & $\sigma_{z}(\mathrm{kPa})$ & $s_{i}(\mathrm{~mm})$ & $s(\mathrm{~mm})$ & Cumulative settlement $(\mathrm{mm})$ \\
\hline 1 & 0.25 & 25.125 & 368.62 & 157.62 & 4.45 & 7.57 & 867.67 & 0.235 & 2.716 & \\
\hline 2 & 0.5 & 25.5 & 124.57 & 121.61 & 4.22 & 7.01 & 677.86 & 1.088 & 3.804 & \\
\hline 3 & 0.5 & 26 & 126.82 & 71.03 & 3.47 & 5.89 & 407.67 & 0.643 & 4.447 & \\
\hline 4 & 0.5 & 26.5 & 61.96 & 41.81 & 2.79 & 4.57 & 247.92 & 0.800 & 5.247 & \\
\hline 5 & 0.5 & 27 & 52.54 & 26.54 & 2.23 & 3.61 & 162.33 & 0.618 & 5.865 & \\
\hline 6 & 0.5 & 27.5 & 53.44 & 18.07 & 1.85 & 2.92 & 114.01 & 0.427 & 6.292 & \\
\hline 7 & 0.5 & 28 & 54.34 & 13.01 & 1.57 & 2.43 & 84.57 & 0.311 & 6.603 & \\
\hline 8 & 0.5 & 28.5 & 55.24 & 9.79 & 1.36 & 2.06 & 65.44 & 0.237 & 6.840 & \\
\hline 9 & 0.5 & 29 & 56.15 & 9.27 & 1.20 & 1.78 & 60.88 & 0.217 & 7.057 & \\
\hline 10 & 0.5 & 29.5 & 57.05 & 6.09 & 1.07 & 1.56 & 42.95 & 0.151 & 7.208 & \\
\hline 11 & 0.5 & 30 & 57.95 & 4.99 & 0.96 & 1.38 & 36.01 & 0.124 & 7.332 & \\
\hline 12 & 2.5 & 31.5 & 60.66 & 2.29 & 0.64 & 0.85 & 18.42 & 0.304 & 7.636 & \\
\hline 13 & 2.5 & 34 & 65.17 & 1.33 & 0.47 & 0.60 & 11.58 & 0.178 & 7.813 & 3.325 \\
\hline
\end{tabular}

is close to the calculated value when considering the grouting effect; this indicates that the optimized parameters are reasonable and feasible. Therefore, the postgrouting pile of the same bearing layer in a given area can be calculated using the proposed method.

\section{Conclusions}

In this study, static load tests were conducted to compare the settlement characteristics of nongrouting and postgrouting piles and the layer-wise summation method was used after optimizing three parameters to predict the settlement of the postgrouting piles. The key findings include

(1) The pile side resistance of the postgrouting pile is approximately trapezoidal according to the field test data. Therefore, the elastic compression coefficient of the pile body is deduced based on the MindlinGeddes method, and the relationship between the elastic compression coefficient and the end resistance ratio is obtained.

(2) By establishing the relationship between the compression modulus and the gravity stress, as well as the static cone resistance, two methods for calculating the compression modulus in this area are obtained.

(3) The end resistance ratio and pile diameter after grouting can be improved according to the test data. The statistical analysis results indicate that the end resistance ratio improvement coefficient is 0.8 and The diameter of piles after grouting is 1.05 times that of nongrouting piles. A comparison of the calculated settlement with the actual settlement for different settlement empirical coefficients under various loads indicates that the settlement empirical coefficient in this area is 0.4 .

(4) The results obtained from the layer-wise summation method after parametric optimization are basically 


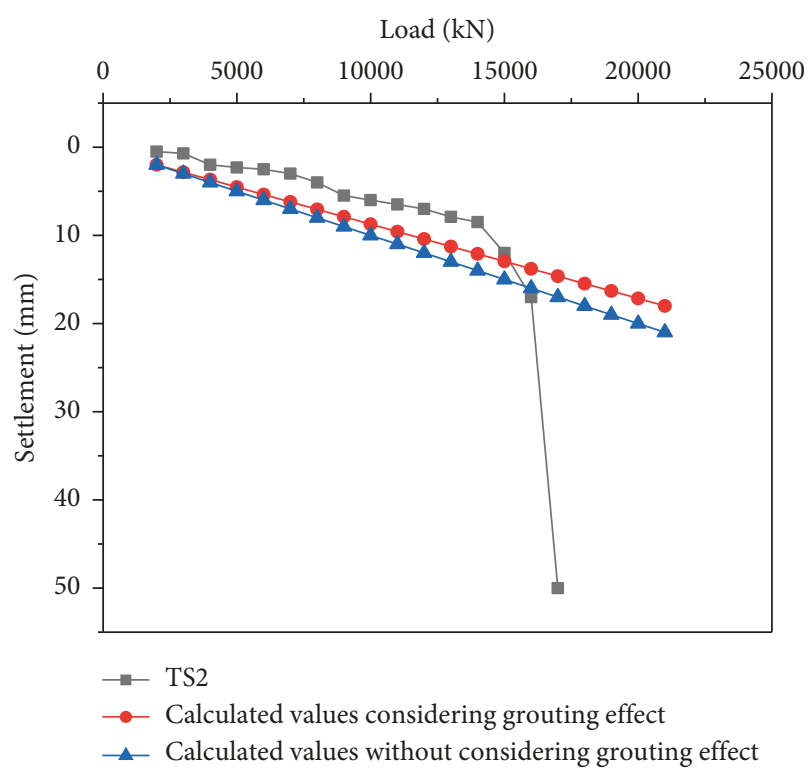

FIGURE 17: Comparison of actual values and calculated values of the TS2 pile settlement.

consistent with the measured values for the postgrouting pile example in this project.

\section{Data Availability}

The data used to support the findings of this study are available from the corresponding author upon request.

\section{Conflicts of Interest}

The authors declare that there are no conflicts of interest regarding the publication of this paper.

\section{Acknowledgments}

This research was funded by the National Key R\&D Program of China (no. 2018YFC0808606) and the Project on Social Development of Shaanxi Provincial Science (no. 2018SF382).

\section{References}

[1] Z. Hu, K. Du, J. Lai, and Y. Xie, "Statistical analysis of influence of cover depth on loess tunnel deformation in NW China," Advances in Civil Engineering, vol. 2019, Article ID 2706976, 12 pages, 2019.

[2] J. Lai, J. Qiu, H. Fan, Q. Zhang, J. Wang, and J. Chen, "Fiber bragg grating sensors-based in-situ monitoring and safety assessment of loess tunnel," Journal of Sensors, vol. 2016, Article ID 8658290, 10 pages, 2016.

[3] H. Xing and L. Liu, "Field tests on influencing factors of negative skin friction for pile foundations in collapsible loess regions," International Journal of Civil Engineering, vol. 16, no. 10, pp. 1413-1422, 2018.

[4] Y. Li, S. Xu, H. Liu, E. Ma, and L. Wang, "Displacement and stress characteristics of tunnel foundation in collapsible loess ground reinforced by jet grouting columns," Advances in Civil Engineering, vol. 2018, Article ID 2352174, 16 pages, 2018.
[5] Y. Zhang, Z. Song, X. Weng, and Y. Xie, “A new soil-water characteristic curve model for unsaturated loess based on wetting-induced pore deformation," Geofluids, vol. 2019, p. 13, 2019.

[6] K. Fang, Z. Zhang, J. Zou, and Z. Wang, "Laboratory studies on pressure filtration in post-grouting of drilled shaft tips in Clay," Geotechnical Testing Journal, vol. 35, no. 4, pp. 665-671, 2012.

[7] O. Safaqah, R. Bittner, and X. Zhang, "Post-grouting of drilled shaft tips on the Sutong Bridge: a case history. Contemporary issues in deep foundations," in Proceedings of the Geo-Denver, February 2007.

[8] J. Lai, S. Mao, J. Qiu et al., "Investigation progresses and applications of fractional derivative model in geotechnical engineering," Mathematical Problems in Engineering, vol. 2016, Article ID 9183296, 15 pages, 2016.

[9] X. Duan, F. H. Kulhawy, and D. M. ASCE, "Tip post-grouting of slurry-drilled shafts in soil: Chinese experiences," Contemporary Topics in Deep Foundations, in Proceedings of the International Foundation Congress and Equipment Expo 2009, Orlando, FL, USA, March 2009.

[10] Z.-M. Zhang, J. Yu, G.-X. Zhang, and X.-M. Zhou, "Test study on the characteristics of mudcakes and in situ soils around bored piles," Canadian Geotechnical Journal, vol. 46, no. 3, pp. 241-255, 2009.

[11] G. Dai, W. Gong, X. Zhao, and X. Zhou, "Static testing of pilebase post-grouting piles of the Suramadu bridge," Geotechnical Testing Journal, vol. 34, no. 1, pp. 34-49, 2010.

[12] Y. Fang, Z. Chen, L. Tao, J. Cui, and Q. Yan, "Model tests on longitudinal surface settlement caused by shield tunnelling in sandy soil," Sustainable Cities and Society, vol. 47, 2019.

[13] Z. Zhou, C. Ren, G. Xu, H. Zhan, and T. Liu, "Dynamic failure mode and dynamic response of high slope using shaking table test," Shock and vibration, vol. 2019, Article ID 4802740, 19 pages, 2019.

[14] Q.-q. Zhang and Z.-m. Zhang, "A simplified nonlinear approach for single pile settlement analysis," Canadian Geotechnical Journal, vol. 49, no. 11, pp. 1256-1266, 2012.

[15] W. D. Guo and M. F. Randolph, "An efficient approach for settlement prediction of pile groups," Géotechnique, vol. 49, no. 2, pp. 161-179, 1999.

[16] Q.-q. Zhang, S.-w. Liu, R.-f. Feng, and X.-m. Li, “Analytical method for prediction of progressive deformation mechanism of existing piles due to excavation beneath a pile-supported building," International Journal of Civil Engineering, 2018.

[17] H. G. Poulos and E. H. Davis, Pile foundation analysis and design, Wiley Press, New York, NY, USA, 1980.

[18] R. Butterfield and P. K. Banerjee, "The elastic analysis of compressible piles and pile groups," Géotechnique, vol. 21, no. 1, pp. 43-60, 1971.

[19] M. F. Randolph and C. P. Wroth, "Analysis of deformation of vertically loaded piles," Journal of the Geotechnical Engineering Division, vol. 104, no. 12, pp. 1465-1488, 1978.

[20] J. Lai, K. Wang, J. Qiu, F. Niu, J. Wang, and J. Chen, "Vibration response characteristics of the cross tunnel structure," Shock and Vibration, vol. 2016, p. 16, 2016.

[21] I. Said, V. De Gennaro, and R. Frank, "Axisymmetric finite element analysis of pile loading tests," Computers and Geotechnics, vol. 36, no. 1-2, pp. 6-19, 2009.

[22] Z. Y. Ai and J. Han, "Boundary element analysis of axially loaded piles embedded in a multi-layered soil," Computers and Geotechnics, vol. 36, no. 3, pp. 427-434, 2009.

[23] E. M. Comodromos, M. C. Papadopoulou, and I. K. Rentzeperis, "Pile foundation analysis and design using experimental data 
and 3-D numerical analysis," Computers and Geotechnics, vol. 36, no. 5, pp. 819-836, 2009.

[24] J. Lai, H. Liu, J. Qiu et al., "Stress analysis of CFG pile composite foundation in consolidating saturated mine tailings dam," Advances in Materials Science and Engineering, vol. 2016, Article ID 3948754, 12 pages, 2016.

[25] Q.-q. Zhang, S.-w. Liu, S.-m. Zhang, J. Zhang, and K. Wang, "Simplified non-linear approaches for response of a single pile and pile groups considering progressive deformation of pilesoil system," Soils and Foundations, vol. 56, no. 3, pp. 473484, 2016

[26] L. Duan, Y. Zhang, and J. Lai, "Influence of ground temperature on shotcrete-to-rock adhesion in tunnels: a review," Advances in Materials Science and Engineering, vol. 2019, p. 12, 2019.

[27] Z. Zhang and Q. Zhang, "Experimental study on mechanical properties of post-grouting compressive pile," Chinese Journal of Rock Mechanics and Engineering, vol. 28, no. 3, pp. 475482, 2009, in Chinese.

[28] L. Zou, Study on settlement characteristics of post grouting pile group foundation, Ph.D. thesis, Southwest Jiaotong University, Chengdu, Sichuan, 2010, in Chinese.

[29] K. Fang, Grout-soil interaction during base grouting and its effects on the behavior of grouted pile, Ph.D. thesis, Zhejiang University, Hangzhou, China, 2013, in Chinese.

[30] X. L. Luo, D. Y. Li, Y. Yang, and S. R. Zhang, "Spatiotemporal Traffic Flow Prediction with KNN and LSTM," Journal of Advanced Transportation, vol. 2019, Article ID 4145353, 10 pages, 2019.

[31] Z. Zhou, J. Lei, S. Shi, and T. Liu, "Seismic response of aeolian sand high embankment slopes in shaking table tests," Applied Sciences, vol. 9, no. 4, p. 15, 2019.

[32] Ministry of Housing and Urban-Rural Construction of the People's Republic of China, Chinese Technical Code For Building Pile Foundations JGJ94-2008, Architecture and Building Press, Beijing, China, 2008, in Chinese.

[33] S.-c. Li, Q. Zhang, Q.-q. Zhang, and L.-p. Li, "Field and theoretical study of the response of super-long bored pile subjected to compressive load," Marine Georesources and Geotechnology, vol. 34, no. 1, pp. 71-78, 2016.

[34] Ministry of Housing and Urban-Rural Construction of the People's Republic of China, Chinese Technical Code For testing of building Foundation Piles JGJ106-2014, Architecture and Building Press, Beijing, China, 2014, in Chinese.

[35] Z. F. Wang, S. L. Shen, and G. Modoni, "Enhancing discharge of spoil to mitigate disturbance induced by horizontal jet grouting in clayey soil: theoretical model and application," Computers and Geotechnics, vol. 111, pp. 222-228, 2019.

[36] Ministry of Housing and Urban-Rural Construction of the People's Republic of China, Chinese Technical Code for Design of Concrete Structures GB50010-2010, Architecture and Building Press, Beijing, China, 2010, in Chinese.

[37] R. D. Mindlin, "Force at a point in the interior of a semiinfinite solid," Physics, vol. 7, no. 5, pp. 195-202, 1936.

[38] J. D. Geddes, "Stresses in foundation soils due to vertical subsurface loading," Géotechnique, vol. 16, no. 3, pp. 231-255, 1966.

[39] B. Zhang, X. Fu, B. Huang, and C. Mei, "Calculation of pile foundation settlement based on Mindlin-Geddes method," Industrial Construction, vol. 44, no. S1, pp. 862-865, 2014.

[40] A. R. Zheng, "Post-grouting bored pile technology," IOP Conference Series: Earth and Environmental Science, vol. 61, article 012057, 2017.
[41] T. Wang, "New stress calculation method for Mindlin formula considering impact of piles diameters," Building structure, vol. 36, no. 10, pp. 46-49, 2006.

[42] L. Duan, W. Lin, J. Lai, and P. Zhang, "Vibration characteristic of high-voltage tower influenced by adjacent tunnel blasting construction," Shock and Vibration, vol. 2019, Article ID 8520564, 14 pages, 2019.

[43] Z. Zhou, Y. Zhao, Z. Chen, X. Du, and Z. Wu, "Mesomechanism of compaction grouting in soil based on particle flow method," Journal of Central South University (Science and Technology), vol. 48, no. 2, pp. 465-472, 2017, in Chinese. 


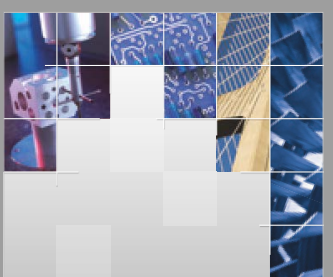

\section{Enfincering}
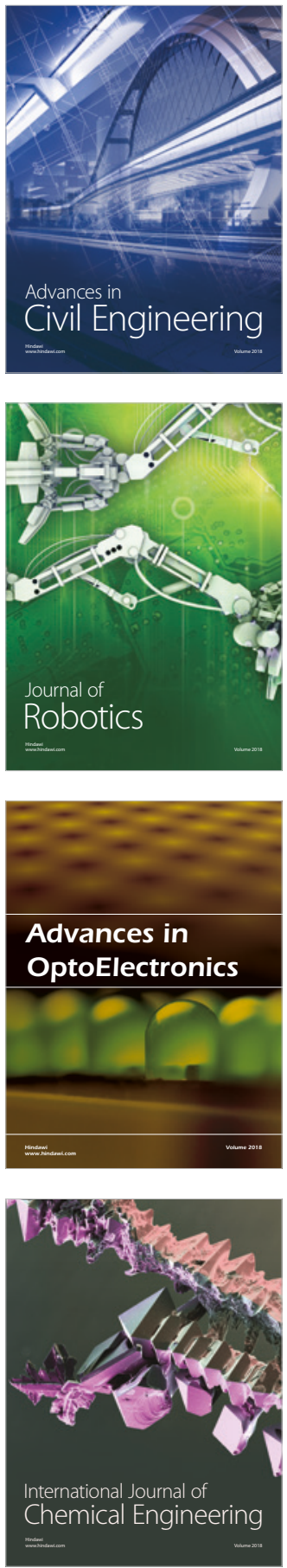

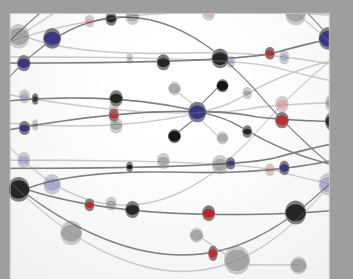

\section{Rotating \\ Machinery}

The Scientific World Journal

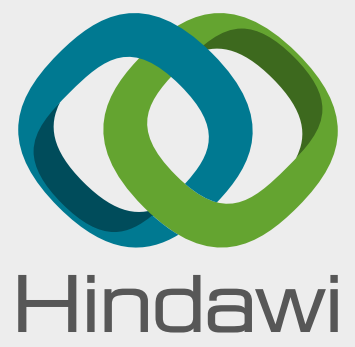

Submit your manuscripts at

www.hindawi.com
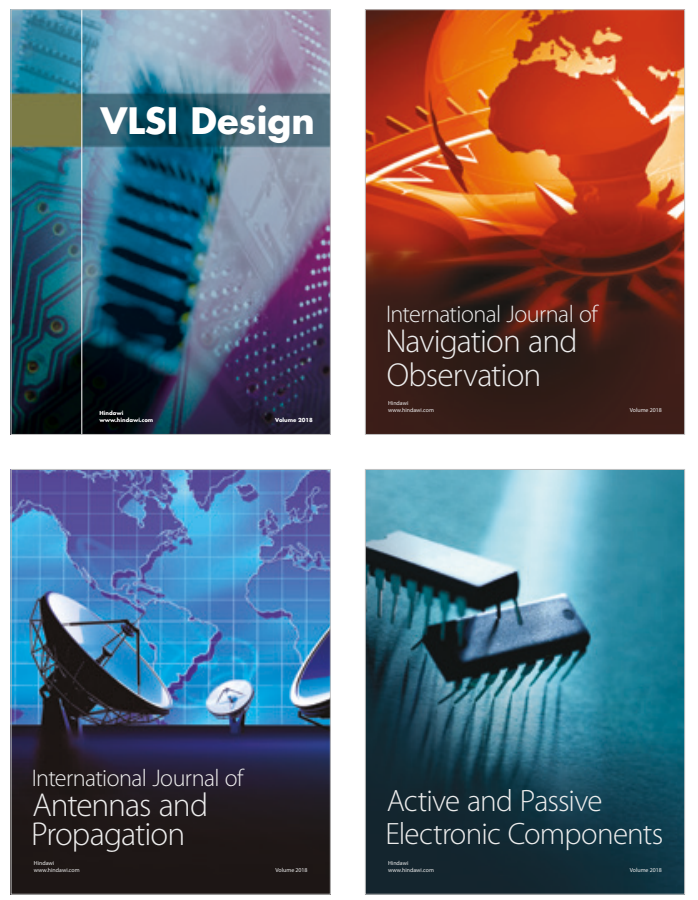
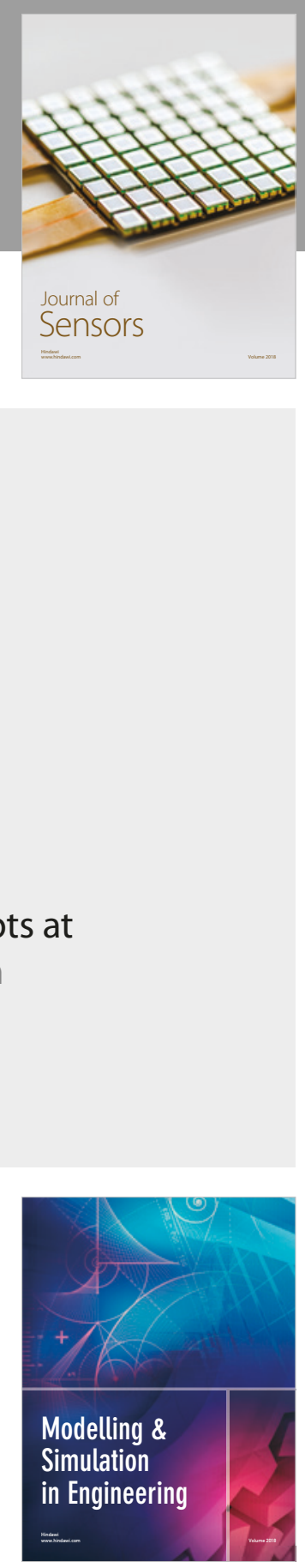

\section{Advances \\ Multimedia}
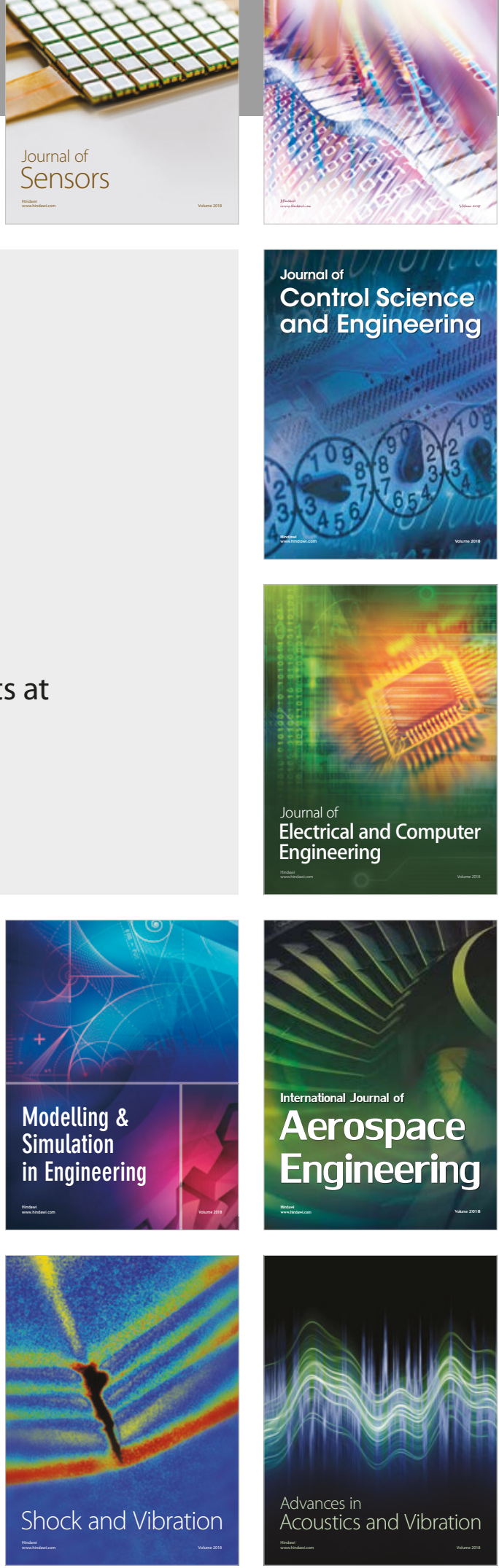